\title{
DISCUSSÃO DA EVOLUÇÃO DA CALDEIRA VULCÂNICA DE POÇOS DE CALDAS (MG) A PARTIR DE UMA ANÁLISE PEDOGEOQUÍMICA EM UMA TOPOSSEQUÊNCIA
}

\author{
DISCUSSION OF THE POCOS DE CALDAS (MG) VOLCANIC CALDERA \\ EVOLUTION FROM A TOPOSEQUENCE PEDOGEOCHEMICAL ANALYSIS
}

\author{
Diego de Souza Sardinha \\ Instituto de Ciência e Tecnologia, Universidade Federal de Alfenas \\ Rodovia José Aurélio Vilela, no 11.999, Poços de Caldas, Minas Gerais, CEP: 37715-400, Brasil \\ E-mail: diegosardinha@yahoo.com.br
}

Letícia Hirata Godoy Instituto de Geociências e Ciências Exatas, Universidade Estadual Paulista Avenida 24-A, $n^{\circ}$ 1515, Rio Claro, São Paulo, CEP: 13506-900, Brasil

E-mail:leticiahirata@gmail.com

Jairo Roberto Jiménez-Rueda Instituto de Geociências e Ciências Exatas, Universidade Estadual Paulista Avenida 24-A, $n^{\circ}$ 1515, Rio Claro, São Paulo, CEP: 13506-900, Brasil E-mail: jairorjr@rc.unesp.br

Maria Margarita Torres Moreno Instituto de Geociências e Ciências Exatas, Universidade Estadual Paulista Avenida 24-A, $n^{\circ}$ 1515, Rio Claro, São Paulo, CEP: 13506-900, Brasil

E-mail:mmoreno@rc.unesp.br

\begin{tabular}{l} 
Informações sobre o Artigo \\
\hline Data de Recebimento: \\
10/11/2014 \\
Data de Aprovação: \\
06/04/2015
\end{tabular}

\section{Palavras-chave:}

Pedoestratigrafia;

Pedogeomorfologia; Evolução do Relevo.

\section{Keywords:}

Pedostratigraphy;

Pedogeomorphology; Relief

Evolution.

\section{Resumo:}

A análise pedogeoquímica refere-se aos constituintes químicos do perfil de alteração, originados pelo intemperismo dos minerais das rochas, principal fonte natural destes elementos. O desenvolvimento ordenado de um perfil de alteração pode ser interrompido inúmeras vezes por mudanças climáticas ou em consequência da intervenção mais abrupta dos agentes geomórficos. O manto de alteração estudado está localizado no interior da caldeira vulcânica do Complexo Alcalino de Poços de Caldas (MG), apresenta uma extensão de aproximadamente 150 metros e encontra-se deslocado por fraturas/falhas em dez níveis/volumes de alterações intempéricas (VAI's). A evolução sob as condicionantes geoquímicas aplicadas nos VAI's, indicam ao menos três principais sequências pedogênicas/ pedogeoquimicas: (i) topo do perfil, formação em ambiente árido que posteriormente lixiviou e/ou precipitou na forma de lateritas durante o tropicalismo de alta pluviosidade; (ii) porção média do perfil, tropicalismo subúmido/subseco em condições de reativação tectônica associada a vulcanismos; (iii) base do perfil, 
latossolização/plintificação com posterior implosão ou abatimento da caldeira e acúmulo de mantos residuais que recobriram esses perfis, deixando em seu interior partes basais deste alto estrutural.

\begin{abstract}
:
The pedogeochemical analysis refers to the chemical constituents of the weathering profile, which are originated by weathering of the rock minerals, the main natural source of these elements. The ordered development of a weathering profile can be interrupted countless times by climatic changes or as a consequence of a more abrupt intervention by geomorphic agents. The studied weathering cover is located within the volcanic caldera of Poços de Caldas Alkaline Complex (MG), presents an extension of $150 \mathrm{~m}$ and is displaced by fractures/faults in ten weathering alteration levels/volumes (WAV's). The evolution under the geochemical constraints applied in the WAV's indicate at least three principal pedogenic/pedogeochemical sequences: (i) top of the profile, arid environment formation that subsequently lixiviated and/or precipitated as laterites during the high rainfall tropicalism; (ii) middle portion of the profile, sub-humid/sub-dry tropicalism with tectonic reactivation conditions related to volcanism; (iii) bottom of the profile, oxisols and plinthosols formation followed by the implosion or drop of the caldera and accumulation of residual mantles, which covered these profiles, leaving inside the lower portions of the structural high.
\end{abstract}

\section{Introdução e Objetivo}

Solos e paisagens analisados a partir de um conceito de evolução policíclica evidenciam que o desenvolvimento ordenado de um perfil de solo pode ser interrompido inúmeras vezes por mudanças climáticas ou em consequência da intervenção mais abrupta dos agentes geomórficos, truncando-se o perfil do solo por erosão, ou ainda pelo sepultamento de depósitos de material novo, em solo preexistente (JIMENEZ-RUEDA et al., 1998).

Para se estudar o processo evolutivo de solos, a caracterização do relevo deve ser levada em conta, visto que este influencia a intensidade do fluxo de água ao longo do perfil de alteração, podendo acelerar as reações químicas do intemperismo, promovendo o transporte de sólidos ou de materiais em solução e produzindo efeitos que se traduzem em diferentes tipos de solo, nas diversas posições geomorfológicas (BARBOSA, et al.., 2009). Desta maneira, um manto de alteração poderá registrar uma sucessão de ambientes como também a história geomórfica da forma do terreno em que estiver situado (VIEIRA, 1988). Para tentar decifrar esta sequência de eventos, pode-se executar a análise de solos através do enfoque geoquímico definindo-se, portanto, a análise pedogeoquímica.

A geoquímica de superfície e sua ramificação, denominada Pedogeoquímica, revestem-se de grande importância no estudo da pedogênese, permitindo o entendimento dos processos de alteração que ocorrem ao longo da evolução pedológica, pois avaliam o comportamento dos elementos químicos, a partir da distribuição e migração destes elementos, e as reações químicas envolvidas ao longo do processo evolutivo, desde a rocha fresca até o sólum (LACERDA et al.., 2002a). O intemperismo dos minerais constituintes das rochas é a principal fonte natural dos elementos químicos e os processos pedológicos que ocorrem nas diferentes fases de formação do solo controlam a dinâmica e a disponibilidade destes elementos no solo. O intemperismo é um processo tipicamente destrutivo, que permite o desenvolvimento de novos minerais a partir daqueles alterados (MELFI \& PEDRO, 1977). São originadas partículas minerais discretas (produtos residuais) presentes na rocha matriz, que permanecem mais ou menos inalteradas, ao lado de novos minerais formados/transformados por intemperismo, além de materiais em solução (SUGUIO, 2003).

Para avaliar a distribuição e migração desses elementos químicos ao longo da intemperização química, deve-se recorrer ao balanço químico de massa entre o material de origem e os produtos resultantes destas alterações (LACERDA et al.., 2002b). Determinar a mobilidade geoquímica que ocorre durante o intemperismo pode ajudar a estabelecer uma sequência de alteração em determinado ambiente no manto estudado. Diversos trabalhos foram realizados com o objetivo de determinar a mobilidade de elementos químicos durante o processo de alteração das rochas e formação dos solos (RUXTON, 1968; COLMAN, 1982; HUDSON, 1988; BRIMHALL et al.., 1991; HODSON et al.., 1996; ANDERSON et al.., 2002; HODSON et al.., 2002; PRICE \& VEBEL, 2003; LASHERAS ADOT et al.., 2006; HASKINS, 2006). 
O município de Poços de Caldas (MG) situa-se, em grande parte, no interior do Complexo Alcalino da caldeira vulcânica de Poços de Caldas, que constitui uma estrutura circular com $35 \mathrm{~km}$ de diâmetro no eixo NW - SE e $30 \mathrm{~km}$ no eixo NE - SW, com área aproximada de $800 \mathrm{~km}^{2}$ (CHAPMAN et al.., 1991). Dentro deste contexto, o presente trabalho tem como objetivo analisar um manto de alteração nas suas características laterais, assim como, a análise pedogeoquímica de um perfil representativo neste manto de alteração localizado na porção noroeste da caldeira vulcânica de Poços de Caldas (MG). O estudo das sequências de alteração através da mobilidade geoquímica possibilita a identificação das alternâncias climáticas e de remodelações das formas de relevo do terreno, processos pedogenéticos vinculados à dinâmica interna e externa, que ocorreram neste local.

\section{Materiais e Métodos}

A área de estudo se destaca de outros locais na Caldeira Vulcânica de Poços de Caldas e foi escolhida por apresentar características diferenciadas em um mesmo afloramento de corte de estrada, único observado na região por ser constituído de uma sucessão de distintos materiais bastante intemperizados e truncados entre si. Com isso, os trabalhos de campo foram iniciados através das descrições morfogenéticas do manto de alteração, seguido pelas coordenadas e altitude (GPS - Global Positioning System, modelo Garmin - Map 62S), fraturamento, direção e mergulho das estruturas (bússola Brunton Pocket Compass Model DQL 8), usos do solo, cobertura vegetal e litologia.

Em um perfil representativo do manto de alteração, que se encontra menos truncado e com uma quantidade maior de diferenciação de cores entre os horizontes, foram realizadas as descrições morfológicas: espessura (trena métrica); transição (plana, ondulada, irregular e descontínua); cor (carta de cores Munsell de 2010); textura (sensações táteis); estrutura (laminar, prismática, colunar, blocos angulares, blocos subangulares e granular); consistência (seco, úmido e molhado); filmes de matéria orgânica, ferro, outros coloides; e solubilidade/precipitação das argilas.

A natureza de cutans, dominância, concreções, nódulos, constituição e origem, assim como a abundância de seixos, forma, tamanho e composição também foram descritas para determinar as propriedades e características dos dez volumes de alterações intempéricas (VAI's) identificados. Estas propriedades e características foram utilizadas para determinar os registros deixados pelas ações/interações dos fatores e processos que deram origem ou elaboraram a paisagem estudada.

As amostras dos dez VAI's também foram encaminhadas para análise granulométrica, mineralógica e geoquímica nos Laboratórios de Difração de Raios X e Geoquímica do Departamento de Petrologia e Metalogenia (DPM) do IGCE da UNESP de Rio Claro (SP). A distribuição do tamanho das partículas foi obtida em equipamento Malvern via úmida, pela técnica de espalhamento de luz laser utilizando três gotas de hexametafosfato de sódio $10 \%$ como dispersante e 15 segundos de ultrassom, para tamanho de partícula menor que $400 \mu \mathrm{m}$. As análises mineralógicas foram realizadas em difratômetro de raios $X$ Panalytical Xpert Pro (MPD) com radiação $\mathrm{Cu}(\mathrm{WL}=1,542 \AA)$ e tempo por passo de 1 segundo. Foram realizadas análises na amostra total, e na fração menor que $2 \mu \mathrm{m}$ (amostras orientadas) em três condições: na sua forma natural, tratadas com etilenoglicol (caracterização dos argilominerais expansivos) e queimadas a $500{ }^{\circ} \mathrm{C}$ (observação de mudanças ocorridas como desidratação de esmectitas, desestruturação de caulinitas e identificação dos picos não afetados, entre outros). As análises químicas para a determinação dos elementos maiores na forma de óxidos $\left(\mathrm{SiO}_{2}, \mathrm{TiO}_{2}, \mathrm{Al}_{2} \mathrm{O}_{3}, \mathrm{Fe}_{2} \mathrm{O}_{3}, \mathrm{MnO}\right.$, $\mathrm{MgO}, \mathrm{CaO}, \mathrm{Na}_{2} \mathrm{O}, \mathrm{K}_{2} \mathrm{O}$ e $\mathrm{P}_{2} \mathrm{O}_{5}$ ) foram realizadas por Espectrometria de Fluorescência de Raios X (Phillips, modelo PW 2510), empregando amostras fundidas em matriz de borato. A perda ao fogo (LOI, "Loss on ignition") foi medida por diferença de peso após calcinação a $1000^{\circ} \mathrm{C}$ da amostra seca.

\section{Características Gerais Da Área De Estudo}

O município de Poços de Caldas localiza-se na região sul do estado de Minas Gerais, na divisa com o estado de São Paulo, a $1286 \mathrm{~m}$ de altitude (PREFEITURA MUNICIPAL DE POÇOS DE CALDAS, 2006). O Município possui uma área total de $544 \mathrm{~km}^{2}$, dos quais aproximadamente $85 \mathrm{~km}^{2}$ formam a zona urbana e 459 $\mathrm{km}^{2}$ a zona rural, tendo como limites oito municípios: ao norte, Botelhos e Bandeira do Sul; a leste, Caldas; ao sul, Andradas e a oeste Águas da Prata, São Sebastião da Grama, Caconde e Divinolândia. 
O clima é do tipo Cwb de acordo com a classificação de Koppen, ou seja, mesotérmico com invernos secos e verões brandos. A estação seca ocorre de abril a setembro, com temperatura média de $15^{\circ} \mathrm{C}$ e total médio de chuvas de $315 \mathrm{~mm}$, já a estação chuvosa de outubro a março, com temperatura média de $21^{\circ}$ C e precipitações médias de $1430 \mathrm{~mm}$ (PREFEITURA MUNICIPAL DE POÇOS DE CALDAS, 2007). Ocorrem no município dois tipos básicos de cobertura vegetal, campo e floresta tropical. Os campos são constituídos por gramíneas e elementos arbustivos baixos, e a floresta tropical é de pouca densidade e permite boa entrada de luz solar, o que favorece o crescimento de vegetação arbustiva e herbácea (PMPC, 2012).

A região de Poços de Caldas situa-se na província geomorfológica denominada Planalto Sul de Minas que é subdividido em três unidades: a Superfície do Alto Rio Grande, o Planalto de São Pedro de Caldas e o Planalto de Poços de Caldas. Ao norte do município também ocorre a província geomorfológica denominada Zona Cristalina do Norte, que é subdividida em duas subzonas: a de Amparo e a de São José do Rio Pardo (COMPANHIA DE PESQUISA DE RECURSOS MINERAIS, 1979). Segundo ZAINE et al.., (2008) as zonas que abrangem o município são: (1) Zona do Planalto do Maciço Cristalino, terrenos de rochas cristalinas, pré-cambrianas, formada por morros e morrotes do tipo "meia laranja"; (2) Zonas da Serra Anelar, que possui estrutura circular e compreende as montanhas com topos restritos (Serra de Poços de Caldas, Serra de São Domingos e Serra do Selado); (3) Planalto do Maciço Alcalino Interno, com morros e morrotes de topos arredondados e colinas, planícies aluviais, rampas de colúvio nas proximidades de rios, e depósitos de tálus nas encostas das montanhas da Serra Anelar.

Quanto à geologia, a região de Poços de Caldas está inserida no contexto da Província Mantiqueira, mais precisamente no Complexo Varginha, que compreende rochas anfibolíticas a granulíticas (COMPANHIA DE PESQUISA DE RECURSOS MINERAIS, 1979). Dentro do Complexo Varginha, ocorrem intrusões de corpos alcalinos, pertencentes à Província Alcalina do Brasil Meridional. Estes corpos alcalinos são distribuídos no território nacional ao longo de dois alinhamentos distintos: um NE, que segue a costa brasileira, e outro NW, que se desenvolve do litoral para interior nesta direção (SCHOBBENHAUS et al.., 1984).

O Complexo Alcalino de Poços de Caldas representa uma caldeira vulcânica e situa-se sobre o "Ramo NW" descrito por Schobbenhaus et al.., (1984). Compreende uma suíte de rochas plutônicas e vulcânicas classificadas, principalmente, como fonolitos e nefelina sienitos (SCHORSCHER \& SHEA, 1992). Caldeiras vulcânicas com evolução geológica similar, cujo contexto compreende intrusão de rochas silicáticas alcalinas seguida de atividades carbonáticas, tectonismo, erosão e/ou sedimentação, podem ser observadas na África do Sul, Noruega, Suécia, Rússia, Índia, Canadá, EUA, Brasil, Angola e Malawi (LE BAS, 1977).

A história evolutiva da Caldeira Vulcânica de Poços de Caldas tem início com a elevação do embasamento causando distensões, fraturas e movimentos de massa, seguido de um grande vulcanismo envolvendo nefelina sienitos, lavas fonolíticas e vulcanoclásticas. Seguem-se climas tropicais úmidos com sedimentação e preenchimento dos condutos vulcânicos por grande quantidade de água de chuva e formação de lagos, resultando na subsidência dos blocos subjacentes e consequente formação da caldeira vulcânica (HOLMES et al.., 1992). Posteriormente, ocorrem intrusões de nefelina sienitos, formando diques menores com formas anelares e estruturas circulares e, por fim, a intrusão de eudialita e nefelina sienitos (Figura 1). A região circundante da estrutura da caldeira possui altitudes em torno de $800 \mathrm{~m}$, enquanto as cristas de suas bordas sustentam-se em cotas variando de $1.500 \mathrm{a}$ $1.600 \mathrm{~m}$ e as suas porções internas, em $1.300 \mathrm{~m}$ (ZAINE et al.., 2008).

\section{Resultados e Discussões}

\subsection{Características do manto de alteração}

O manto de alteração estudado apresenta uma extensão de aproximadamente 150 metros, uma sequencia vertical de materiais de aproximadamente $6,5 \mathrm{~m}$ e é constituído por uma sucessão de distintos horizontes (VAI's) bastante intemperizados e truncados entre si. O afloramento de corte de estrada está localizado na rodovia José Aurélio Vilela que liga o município de Poços de Caldas (MG) a Águas da Prata (SP), nas coordenadas $21^{\circ} 48^{\prime} 37^{\prime \prime}$ de latitude Sul e 46 $39^{\prime} 24^{\prime \prime}$ de longitude Oeste (Figura 2). 

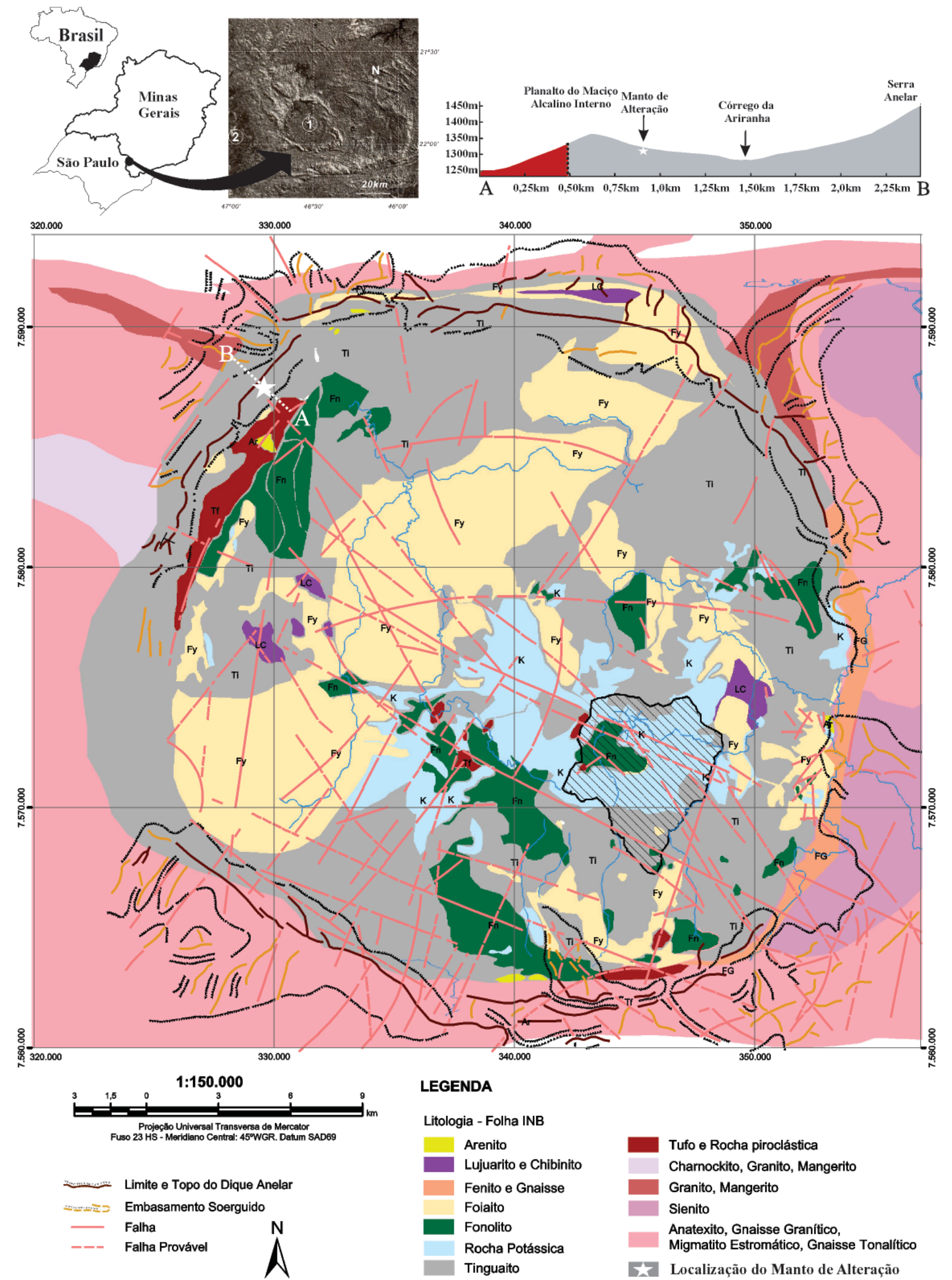

Tufo e Rocha piroclástica

Charnockito, Granito, Mangerito

Granito, Mangerito

Sienito

Anatexito, Gnaisse Granítico,

Migmatito Estromático, Gnaisse Tonalítico

Localização do Manto de Alteração

Figura 1 - Localização da caldeira vulcânica de Poços de Caldas com a área de estudo (manto de alteração). Modificado: TEIXEIRA et al.., 2000; INDÚSTRIAS NUCLEARES DO BRASIL, 2011. 

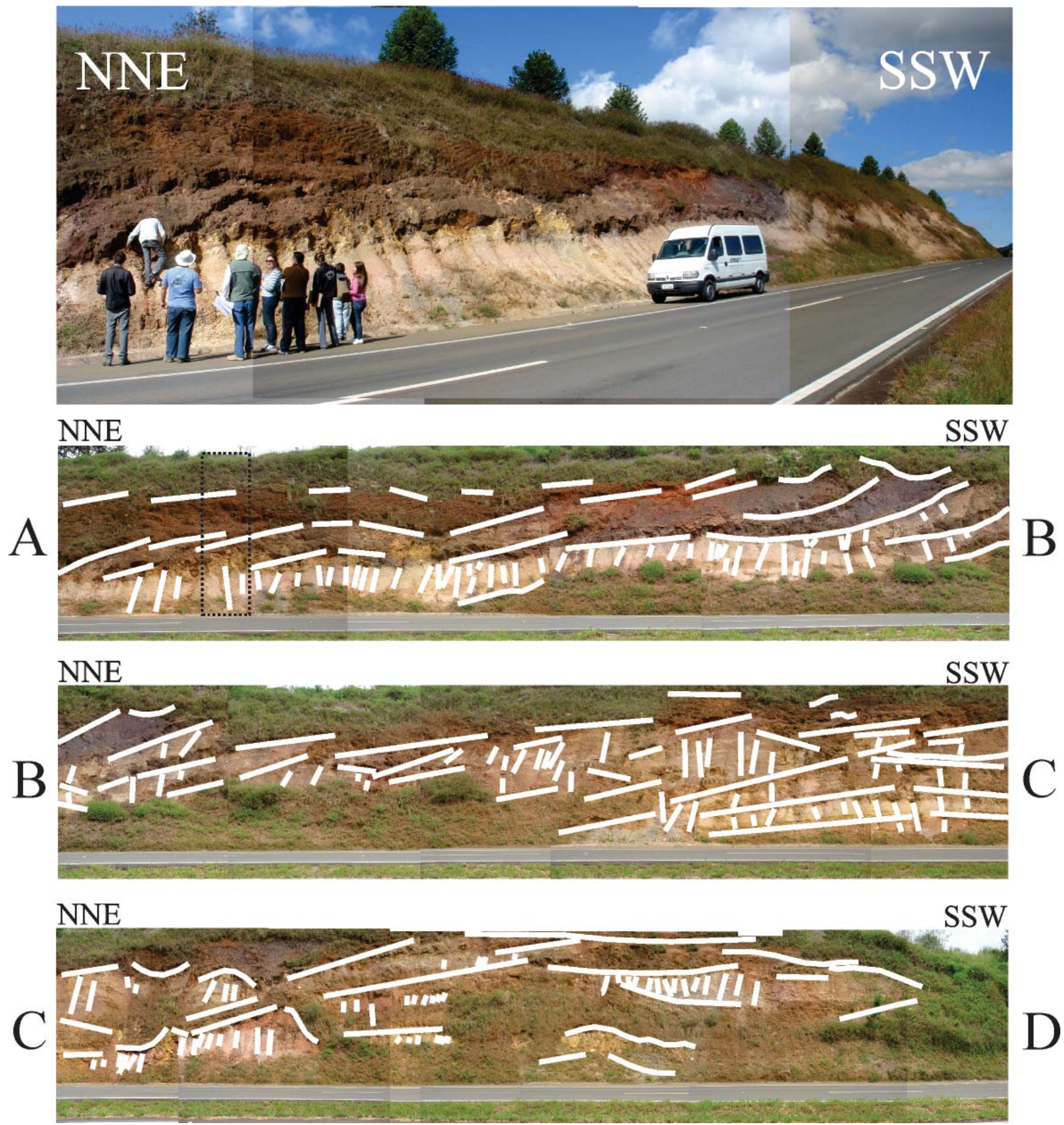

D

Figura 2 - Manto de alteração com os sistemas de fraturamento, horizontais entre as camadas pedoestratigráficas e subverticais na base. Em destaque, hachura no corte A-B, localização do perfil representativo onde foram realizadas descrições morfológicas e coleta de amostras para análise.

O manto de alteração localiza-se no Planalto Alcalino Interno da Caldeira Vulcânica de Poços de Caldas em um relevo que apresenta uma encosta convexa a plana de topos aplainados acompanhando um alinhamento mais serrano a Oeste e um vale aberto amplo deformado por falha de possível transcorrência, modificada por ação deformante mais moderna, dando origem a pequenos horsts e grabens. Esta colina ampla e ligeiramente dissecada, localizada entre o topo e a meia encosta da vertente apresenta aparentemente camadas bandadas que se 
encontram deslocadas por fraturas/falhas em dez níveis, os quais apresentam mega/macro estruturação em prismas colunares com cutans entre planos de fraturamento, assim como cascalheiras fluviais/gravitacionais de fluxo de massa lento/rápido, soterrando mantos plintificados transicionais entre altos e baixos estruturais basais.

No topo do manto de alteração foram observados dois níveis de lateritas, cujas camadas encontram-se falhadas. No meio do corte, há o que aparenta ser uma camada de solo orgânico (escuro), resquício de paleolagos superpostos por fluxos de sedimentos mais grosseiros. $\mathrm{Na}$ porção basal do perfil, observa-se um sistema de fraturamento com quatro direções preferenciais de planos que se repetem com maior ou menor frequência, sendo que se destacam duas direções preferenciais, N-S e E-W subverticais, persistentes e que se repetem continuamente (Figura 2).

\subsection{Análise pedogeoquímica do perfil de alteração}

No perfil representativo do manto de alteração (Figura 3), foram realizadas as descrições morfológicas e análises geoquímicas relativas aos principais óxidos presentes (Tabela 1). Nos VAI's do topo A/Cq, Biqr e Cqir são encontradas as menores concentrações de $\mathrm{SiO}_{2}$, diferente do $\mathrm{Al}_{2} \mathrm{O}_{3}$ com maiores concentrações, indicando que no processo de alteração o teor deste elemento torna-se mais elevado. Quanto a $\mathrm{TiO}_{2}, \mathrm{Fe}_{2} \mathrm{O}_{3}$, $\mathrm{Na}_{2} \mathrm{O}, \mathrm{P}_{2} \mathrm{O}_{5}$ e $\mathrm{CaO}$, maiores teores destes elementos químicos são encontrados na porção média do perfil,

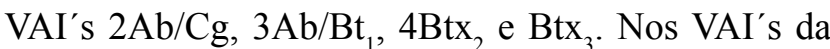
base $5 \mathrm{Bt}_{4}, \mathrm{Bt}_{5} / \mathrm{Crf}$ e Crf estão as maiores concentrações de $\mathrm{SiO}_{2}$ e $\mathrm{K}_{2} \mathrm{O}$ (Tabela 1), permitindo inferir que, em termos gerais, há registro de pelo menos três sequências principais de evolução.
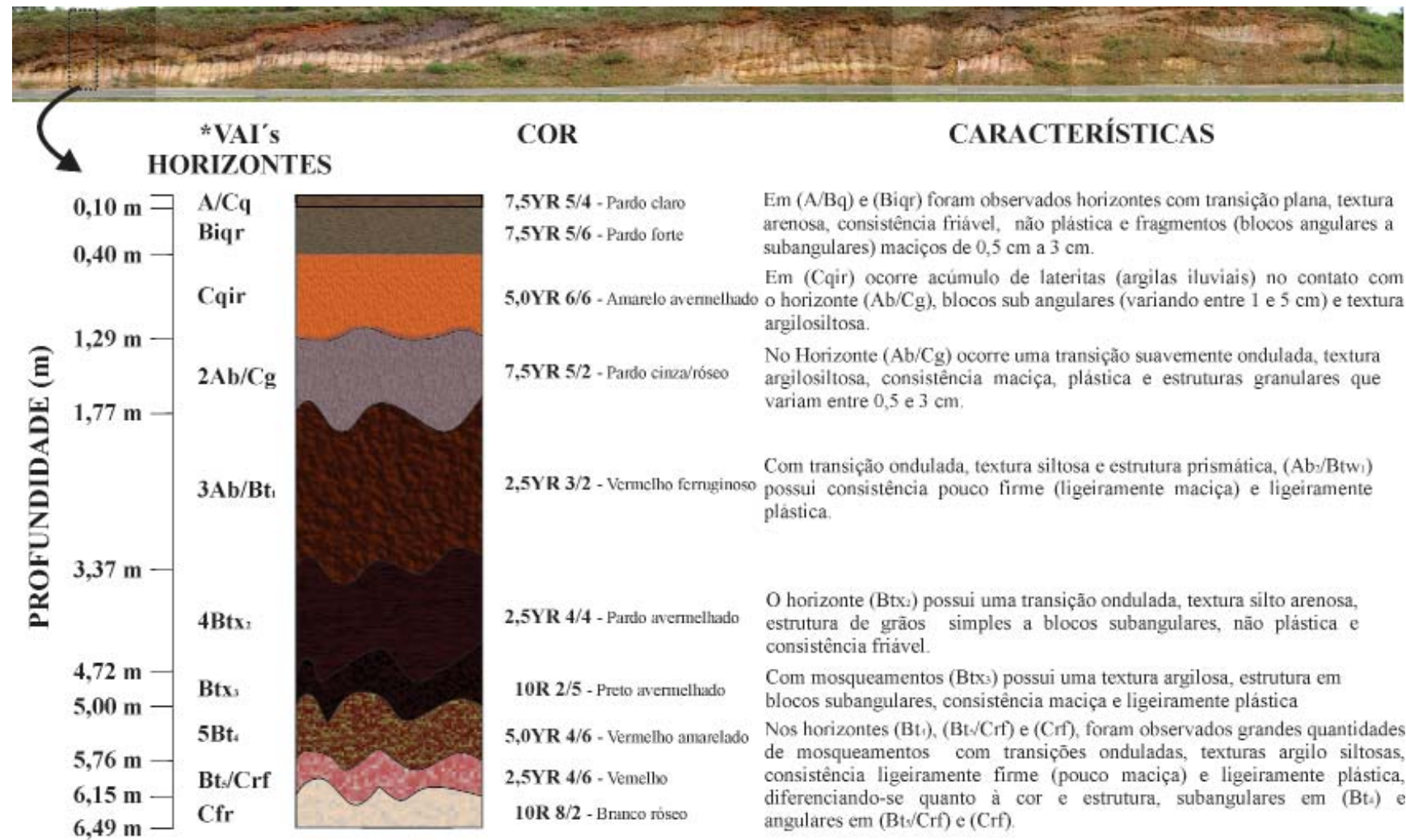

Em $(\mathrm{A} / \mathrm{Bq})$ e (Biqr) foram observados horizontes com transição plana, textura arenosa, consistência friável, não plástica e fragmentos (blocos angulares a subangulares) maciços de $0,5 \mathrm{~cm}$ a $3 \mathrm{~cm}$

Em (Cqir) ocorre acúmulo de lateritas (argilas iluviais) no contato com horizonte $(\mathrm{Ab} / \mathrm{Cg})$, blocos sub angulares (variando entre 1 e $5 \mathrm{~cm}$ ) e textura argilosiltosa

No Horizonte $(\mathrm{Ab} / \mathrm{Cg})$ ocorre uma transição suavemente ondulada, textura argilosiltosa, consistência maciça, plástica e estruturas granulares que variam entre 0,5 e $3 \mathrm{~cm}$

Com transição ondulada, textura siltosa e estrutura prismática, ( $\mathrm{Ab}$ / $/ \mathrm{Btw}$ ) possui consistência pouco firme (ligeiramente maciça) e ligeiramente plástica

O horizonte $\left(\mathrm{Btx}_{2}\right)$ possui uma transição ondulada, textura silto arenosa, estrutura de grãos simples a blocos subangulares, não plástica e consistência friável

Com mosqueamentos ( $\mathrm{Btx}_{3}$ ) possui uma textura argilosa, estrutura em blocos subangulares, consistência maciça e ligeiramente plástica

Nos horizontes $\left(\mathrm{Bt}_{1}\right),(\mathrm{Bt} / \mathrm{Crf})$ e $(\mathrm{Crf})$, foram observados grandes quantidades de mosqueamentos com transiçōes onduladas, texturas argilo siltosas, consistência ligeiramente firme (pouco maciça) e ligeiramente plástica, diferenciando-se quanto à cor e estrutura, subangulares em (Bts) e angulares em (Bt/ $/ \mathrm{Crf})$ e (Crf)

Figura 3 - Localização do perfil representativo com as principais características morfológicas. *VAI's-volume de alterações intempéricas.

Estas variações que acompanham a movimentação da sílica podem ser representadas graficamente utilizando os diagramas de Hacker, com a variação de sílica versus os principais óxidos (ROLLINSON, 1993). O diagrama indica que os óxidos de sódio, cálcio, magnésio e potássio são os elementos mais removidos no processo de intemperismo, o que geralmente não se verifica com os óxidos de alumínio, titânio, fósforo e ferro, já que esses elementos são mobilizados com menor intensidade, ocorrendo um aumento na sua concentração nos solos, quando comparados aos elementos mais facilmente removidos (Figura 4). 
Sardinha D. S. et al.

Tabela 1: Análises químicas dos principais óxidos (\% em peso) nos perfis de alteração.

\begin{tabular}{ccccccccccccc}
\hline${ }^{*} \mathbf{V A I} \mathbf{s}$ & $\mathbf{S i O}_{2}$ & $\mathbf{T i O}_{2}$ & $\mathbf{A l}_{2} \mathbf{O}_{3}$ & $\mathbf{F e}_{2} \mathbf{O}_{3 T}$ & $\mathbf{M n O}$ & $\mathbf{M g O}$ & $\mathbf{C a O}$ & $\mathbf{N a}_{2} \mathbf{O}$ & $\mathbf{K}_{2} \mathbf{O}$ & $\mathbf{P}_{2} \mathbf{O}_{5}$ & $\mathbf{L O I}$ & $\mathbf{S o m a}$ \\
\hline $\mathbf{A} / \mathbf{C q}$ & 13,48 & 2,57 & 51,23 & 3,52 & 0,03 & 0,09 & 0,27 & 0,11 & 0,30 & 0,14 & 28,26 & 100,00 \\
$\mathbf{B i q r}$ & 14,97 & 3,10 & 48,57 & 5,69 & 0,02 & 0,07 & 0,07 & 0,09 & 0,24 & 0,19 & 27,00 & 100,01 \\
$\mathbf{C q i r}$ & 17,77 & 3,03 & 50,17 & 3,90 & 0,03 & 0,07 & 0,05 & 0,10 & 0,32 & 0,16 & 24,40 & 100,00 \\
$\mathbf{2 A b} / \mathbf{C g}$ & 22,10 & 6,87 & 34,72 & 18,95 & 0,03 & 0,03 & 0,12 & 0,11 & 0,08 & 0,62 & 16,38 & 100,01 \\
$\mathbf{3 A b} / \mathbf{B t}_{1}$ & 30,86 & 5,79 & 23,89 & 25,79 & 0,04 & 0,02 & 0,32 & 0,12 & 0,09 & 1,75 & 11,33 & 100,00 \\
$\mathbf{4 B t x}_{2}$ & 50,43 & 4,32 & 16,16 & 19,97 & 0,31 & 0,03 & 0,29 & 0,13 & 0,07 & 1,65 & 6,65 & 100,01 \\
$\mathbf{B t x}_{\mathbf{3}}$ & 20,04 & 6,96 & 17,44 & 41,86 & 0,20 & 0,02 & 0,16 & 0,15 & 0,15 & 1,32 & 11,70 & 100,00 \\
$\mathbf{5 B t}_{\mathbf{4}}$ & 40,08 & 0,75 & 34,46 & 10,35 & 0,02 & 0,14 & 0,03 & 0,08 & 0,08 & 0,21 & 13,82 & 100,02 \\
$\mathbf{B t}_{\mathbf{5}} \mathbf{C r f}$ & 45,50 & 2,94 & 33,86 & 3,90 & 0,11 & 0,07 & 0,05 & 0,11 & 0,79 & 0,33 & 12,32 & 99,98 \\
$\mathbf{C r f}$ & 54,99 & 3,63 & 28,90 & 1,65 & 0,29 & 0,05 & 0,06 & 0,15 & 0,62 & 0,37 & 9,30 & 100,01 \\
$* * \mathbf{R}$ & 52,48 & 0,49 & 20,43 & 3,98 & 0,23 & 0,27 & 1,65 & 7,90 & 8,37 & 0,03 & 2,73 & 98,56 \\
\hline
\end{tabular}

*VAI's - Volume de alterações intempéricas **VALETON et al.. (1997)
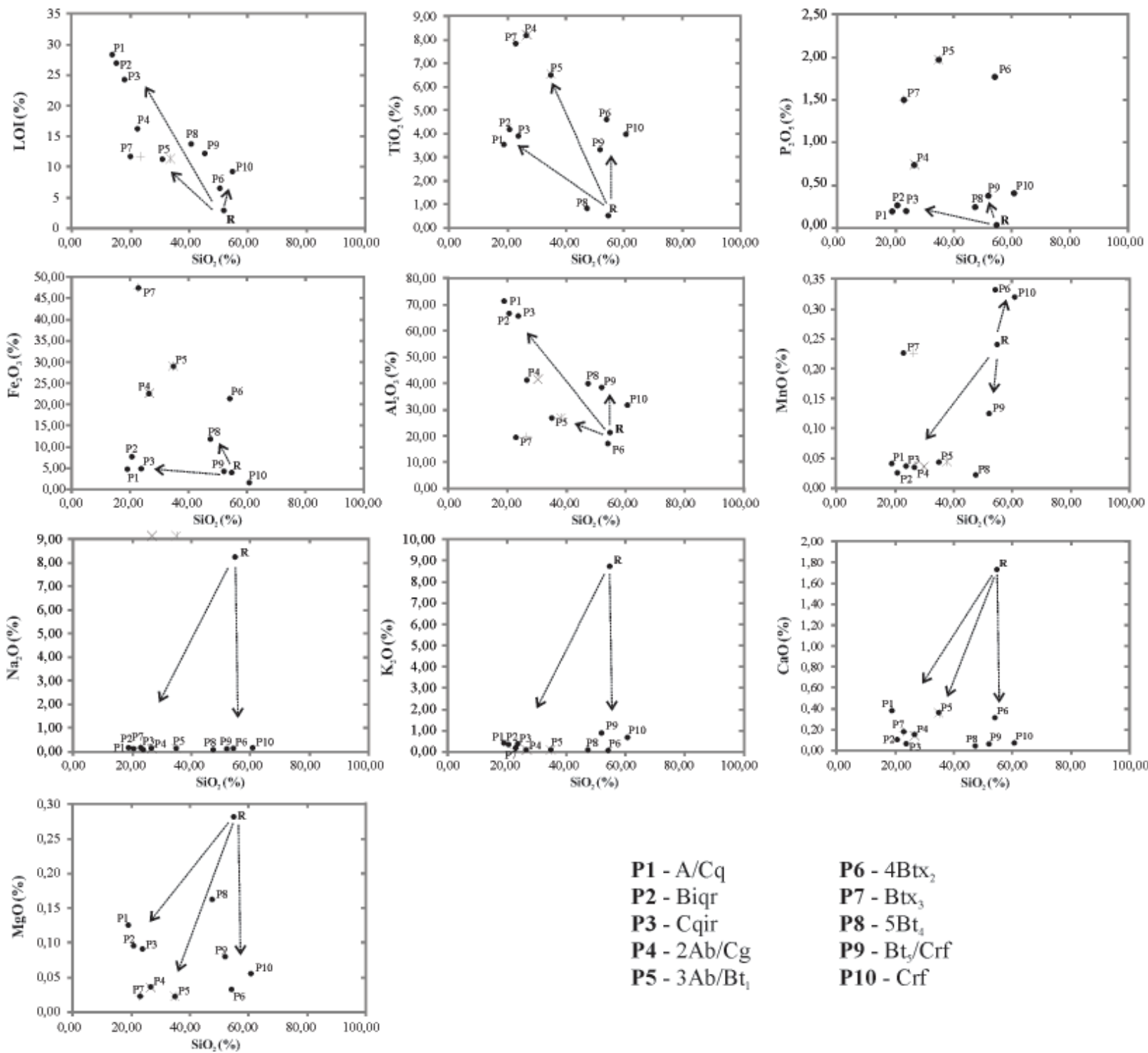

Figura 4 - Projeção dos resultados obtidos nos diagramas de Harker, que apresentam a variação de SiO versus principais óxidos. As flechas indicam o comportamento da alteração das amostras de rochas (R) para as amostras de solos (P1 - A/Cq, P2 - Biqr, P3 - Cqir, P4 - 2Ab/ Cg, P5 - 3Ab/Bt , P6 - 4Btx, P7 - Btx $x_{3}$ P8-5Bt ,P9 - Bt $/$ Crf e P10 - Crf). Dados de rocha (R): VALETON et al.. (1997). 
Nos diagramas de Harker observam-se as tendências para aumento ou redução das concentrações dos óxidos com o aumento de $\mathrm{SiO}_{2}$ relativas à rocha $(\mathrm{R})$, positivas para $\mathrm{LOI}, \mathrm{TiO}_{2}$ e $\mathrm{P}_{2} \mathrm{O}_{5}$ (Figura 4), indicando um possível agrupamento entre os $\mathrm{VAI}^{\prime} \mathrm{s}$ do topo $\mathrm{A} / \mathrm{Cq}$, Biqr e Cqir, porção média VAI's $2 \mathrm{Ab} / \mathrm{Cg}, 3 \mathrm{Ab} / \mathrm{Bt}_{1}$ e $\mathrm{Btx}_{3}$ e da base VAI's 4Btx $2,5 \mathrm{Bt}_{4}, \mathrm{Bt}_{5} / \mathrm{Crf}$ e Crf do perfil de alteração. Para os elementos $\mathrm{Fe}_{2} \mathrm{O}_{3}, \mathrm{Al}_{2} \mathrm{O}_{3}$ e $\mathrm{MnO}$ observam-se variações diferenciadas, empobrecimento de $\mathrm{Fe}_{2} \mathrm{O}_{3}$ com aumento de $\mathrm{SiO}_{2}$ em Crf, empobrecimento de $\mathrm{Al}_{2} \mathrm{O}_{3}$ com aumento de $\mathrm{SiO}_{2}$ em $\mathrm{Btx}_{2}$ e enriquecimento de $\mathrm{MnO}$ com aumento de $\mathrm{SiO}_{2}$ nestes mesmos pontos. Tendências negativas são observadas para os elementos $\mathrm{Na}_{2} \mathrm{O}, \mathrm{K}_{2} \mathrm{O}, \mathrm{CaO}$ e $\mathrm{MgO}$ indicando a perda destes durante o processo de intemperismo.

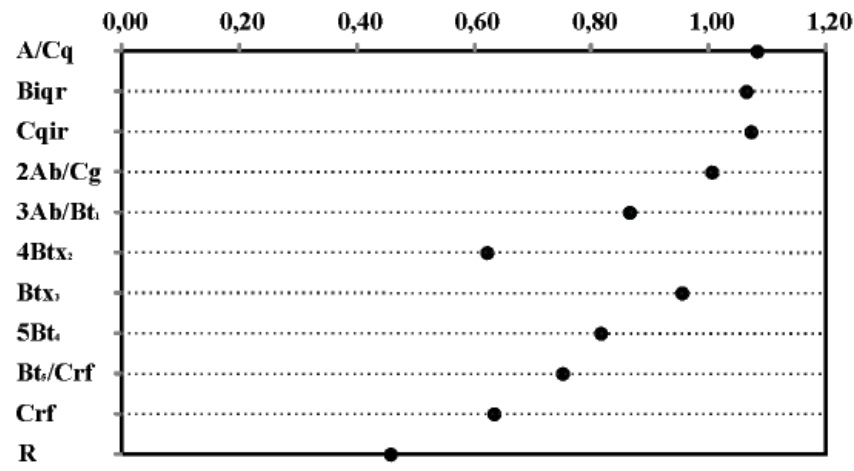

(a)
As concentrações dos elementos considerados potencialmente imóveis, analisados neste trabalho $\left(\mathrm{TiO}_{2}, \mathrm{Al}_{2} \mathrm{O}_{3}\right.$ e $\mathrm{Fe}_{2} \mathrm{O}_{3}$ ), foram utilizadas para normalizar a concentração dos elementos considerados potencialmente móveis $\left(\mathrm{SiO}_{2}, \mathrm{MnO}, \mathrm{MgO}, \mathrm{CaO}, \mathrm{Na}_{2} \mathrm{O}, \mathrm{K}_{2} \mathrm{O}\right.$ e $\mathrm{P}_{2} \mathrm{O}_{5}$ ) em cálculos geoquímicos de balanço de massa, conforme Krauskopf (1995). Na Figura 5 encontram-se os gráficos dos cálculos efetuados em proporção atômica equivalente para os elementos considerados potencialmente imóveis (Figura 5a) e elementos considerados potencialmente móveis (Figura 5b). Os elementos com o comportamento potencialmente imóvel no perfil de intemperismo, VAI's A/Cq, Biqr, Cqir, $2 \mathrm{Ab} / \mathrm{Cg}, 3 \mathrm{Ab} /$ $\mathrm{Bt}_{1}, 4 \mathrm{Btx}_{2}, \mathrm{Btx}_{3}, 5 \mathrm{Bt}_{4}, \mathrm{Bt}_{5} / \mathrm{Crf}$ e $\mathrm{Crf}$, devem ser aqueles que mantém uma forte relação geoquímica com a rocha parental (R) praticamente sem ganho ou perda.

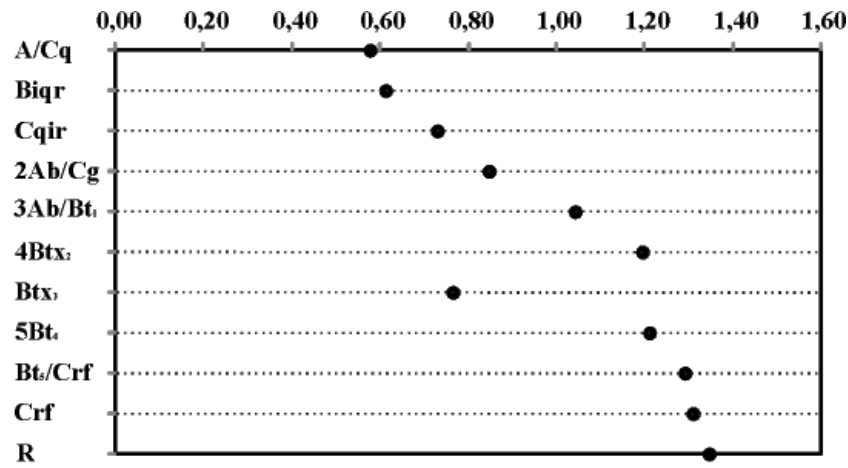

(b)

Figura 5 - Peso molecular equivalente: (a) elementos imóveis ( $\mathrm{TiO}_{2}, \mathrm{Al}_{2} \mathrm{O}_{3}$ e $\left.\mathrm{Fe}_{2} \mathrm{O}_{3}\right)$; (b) elementos móveis ( $\mathrm{SiO}, \mathrm{MnO}, \mathrm{MgO}, \mathrm{CaO}, \mathrm{Na} \mathrm{O}_{2}$, $\mathrm{K}_{2} \mathrm{O}$ e $\mathrm{P}_{2} \mathrm{O}_{5}$ ). Amostras de VAI's (A/Cq, Biqr, Cqir, 2Ab/Cg, 3Ab/Bt $, 4 \mathrm{Btx}_{2}, \mathrm{Btx}_{3}, 5 \mathrm{Bt}_{4}, \mathrm{Bt}_{5} / \mathrm{Crf}$ e Crf) e (R) de VALETON et al.. (1997).

Para os elementos potencialmente imóveis (Figura 5a) nota-se o enriquecimento ao longo do perfil de alteração em relação à amostra de rocha, ao contrário dos elementos potencialmente móveis (Figura 5b), que sofrem lixiviação e empobrecimento. Nos VAI's $4 \mathrm{Btx}_{2} \mathrm{e}$ $\mathrm{Btx}_{3}$ ocorrem quebras na sequência de enriquecimento e empobrecimento. O VAI Btx ${ }_{2}$ possui uma transição ondulada, textura silto arenosa, estrutura de grãos simples a blocos subangulares, não plástica e consistência friável, por outro lado, o VAI Btx 3 possui mosqueamentos e textura argilosa, estrutura em blocos subangulares, consistência maciça e ligeiramente plástica. Estas diferenças podem estar relacionadas ao nível ou oscilação de água no perfil de alteração (fluviais/gravitacionais e/ou de massa lento/rápido).
Os índices (Figura 6) classificam os perfis de alteração por meio da quantidade de sílica relativa (Ki) calculada pela relação molecular $\left(\mathrm{SiO}_{2} / \mathrm{Al}_{2} \mathrm{O}_{3}\right) \mathrm{e}$ $(\mathrm{Kr})$ entre $\left(\mathrm{SiO}_{2}\right) /\left(\mathrm{Al}_{2} \mathrm{O}_{3}+\mathrm{Fe}_{2} \mathrm{O}_{3}\right)$ (RUXTON, 1968). Devido ao fato do índice Ki da caulinita corresponder a 2,0 , esse valor foi estabelecido como limite entre solos muito intemperizados $(\mathrm{Ki}<2,0)$ e pouco intemperizados (Ki > 2,0) (IBGE, 2007), sendo utilizado o mesmo limite para a relação molecular de $\mathrm{Kr}$ (SIQUEIRA et al.., 2014). Os índices WPI e IP proporções da relação de $\mathrm{SiO}_{2}: \mathrm{R}_{2} \mathrm{O}_{3}$ e bases: $\mathrm{R}_{2} \mathrm{O}_{3}$ indicam a mobilidade de $\mathrm{SiO}_{2}$ em relação a bases e $\mathrm{R}_{2} \mathrm{O}_{3}$. O ponto de partida das alterações intempéricas se dá a partir da rocha e/ ou do material regolitizado/sedimentos inconsolidados (COLMAN, 1982). 


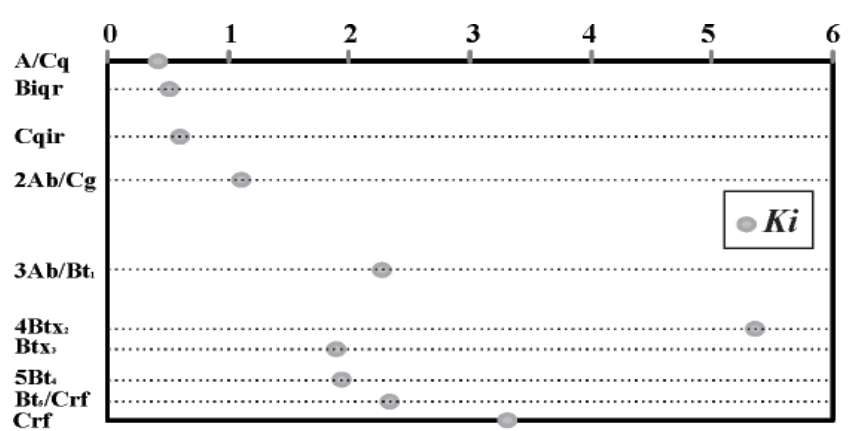

(a)

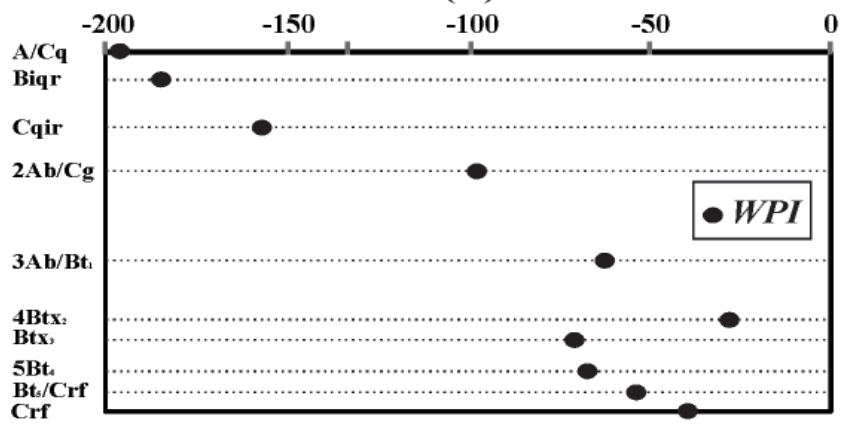

(c)

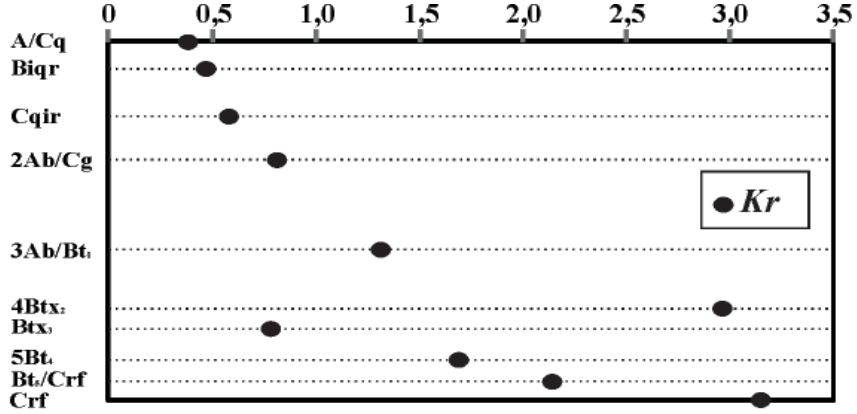

(b)

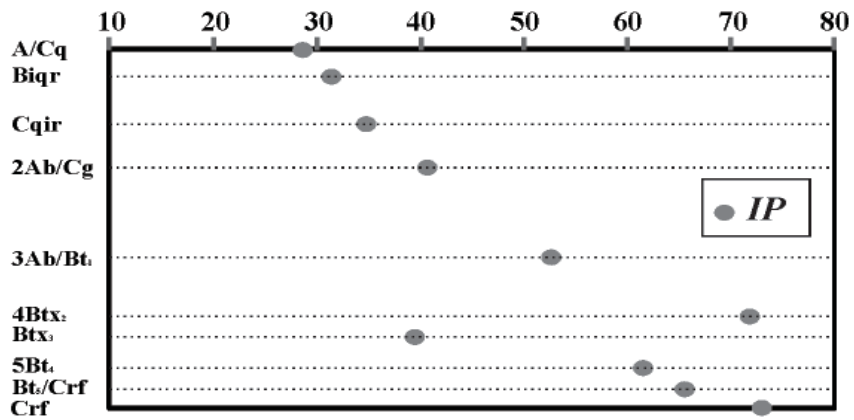

(d)

Figura 6 - Índices de intemperismo: (a) e (b) razão de sílica / sesquióxidos $(\mathrm{Ki})=\left(\mathrm{SiO}_{2} / \mathrm{Al}_{2} \mathrm{O}_{3}\right)$ e $(\mathrm{Kr})=\left(\mathrm{SiO}_{2}\right) /\left(\mathrm{Al}_{2} \mathrm{O}_{3}+\mathrm{Fe}_{2} \mathrm{O}_{3}\right)(\mathrm{RUXTON}$, 1968); (c) indice de intemperismo potencial $(W P I)=100 x\left[\left(\sum\right.\right.$ bases $\left.-\mathrm{H}_{2} \mathrm{O}\right) /\left(\sum\right.$ bases $\left.\left.+\mathrm{SiO}_{2}+\mathrm{R}_{2} \mathrm{O}_{3}\right)\right](\mathrm{COLMAN}, 1982) ;(d)$ indice de produtos $(\mathrm{IP})=100 x\left(\mathrm{SiO}_{2}\right) /\left(\mathrm{SiO}_{2}+\sum \mathrm{R}_{2} \mathrm{O}_{3}\right)(\mathrm{COLMAN}, 1982)$.

Os índices de intemperismo (Figura $6 \mathrm{a}, \mathrm{b}, \mathrm{c}, \mathrm{e} \mathrm{d}$ ) indicam que porcentagem de $\mathrm{Si}^{4+}$ dissolvida pode ter sido parcialmente removida e outra parte, reagido com alumínio dissolvido para formar argilas neoformadas. Estes processos no perfil de alteração podem ter causado o enriquecimento residual e/ou relativo de argilas oxídicas (óxidos e hidróxidos de ferro), além de titânio. Considerando o Ti como elemento de referência (potencialmente imóvel) e normalizando em função de seu teor na rocha, conforme Brimhall et al.., (1991) verifica-se uma perda significativa de todos os elementos analisados neste trabalho, mesmo de $\mathrm{Fe}$ e Al se comparado com a rocha considerada parental, exceto para o VAI $5 \mathrm{Bt} 4$, mas isso pode se dever a um teor muito baixo de Ti nesse material (Figura 4).

No entanto, quando analisadas as intensidades da ação intempérica em função dos resultados dos índices $\mathrm{Ki}, \mathrm{Kr}$, WPI e IP e dos mesmos índices normalizados pela base do perfil de alteração, VAI Crf, com química mais próxima do material parental, é possível algumas sequências intempéricas (Tabela 2). No topo, podem ser identificados três VAI's A/Cq, Biqr e Cqir com índices aproximados, o que pode indicar deposições sucessivas e advindas da mesma fonte e/ou sequências submetidas ao intemperismo atual. Em profundidade, nesta mesma sequência e tomando como material de origem o VAI $4 \mathrm{Btx}_{2}$, este bem como os dois superiores a ele $2 \mathrm{Ab} / \mathrm{Cg}$ e $3 \mathrm{Ab} / \mathrm{Bt}_{1}$ podem corresponder à outra sequência de intemperismo, no entanto, observa-se uma grande alternância, índices diferentes são observados na camada superior $3 \mathrm{Ab} / \mathrm{Bt}_{1}$ e inferior $\mathrm{Btx}_{3}$, quando comparadas com o topo e a base do VAI 4Btx. Na sequência de base do perfil de alteração os VAI's $5 \mathrm{Bt}_{4}, \mathrm{Bt}_{5} / \mathrm{Crf}$ e Crf são mais próximos entre si, o que possivelmente identifica uma outra sequência de intemperismo.

A análise granulométrica pela técnica de espalhamento de luz laser demonstra que o VAI A/Cq possui aproximadamente $35 \%$ de fração de argila e silte entre 0,3 a $10 \mu \mathrm{m}$ e uma fração de areia fina a areia grossa entre 100 e $1000 \mu \mathrm{m}$ na faixa de $13 \%$. Os VAI's Biqr e Cqir possuem faixa granulométrica mais selecionada concentrada no tamanho médio de silte e areia muito fina entre 10 e $100 \mu \mathrm{m}$ e uma porção menor $(\cong 25 \%)$ distribuída na fração de argila e silte entre 0,3 a $10 \mu \mathrm{m}$ (Figura 6). Os VAI's $2 \mathrm{Ab} / \mathrm{Cg}, 3 \mathrm{Ab} / \mathrm{Bt}_{1}, 4 \mathrm{Btx}_{2}$ e Btx 3 possuem uma distribuição granulométrica não selecionada, 
Tabela 2: Descrições dos VAI's analisados com os índices de intemperismo normalizados (n) pela base do perfil de alteração VAI's (Crf).

\begin{tabular}{ccccccccc}
\hline $\mathbf{V A I}^{\prime} \boldsymbol{s}$ & $\boldsymbol{K i}$ & $\boldsymbol{K i} \boldsymbol{n}$ & $\boldsymbol{K} \boldsymbol{r}$ & $\boldsymbol{K} \boldsymbol{n}$ & $\boldsymbol{P I}$ & $\boldsymbol{P I} \boldsymbol{n}$ & $\boldsymbol{W I P}$ & WIP $\boldsymbol{~}$ \\
\hline $\mathbf{A} / \mathbf{C q}$ & 0,447 & 0,138 & 0,429 & 0,137 & 28,765 & 0,394 & $-196,444$ & 4,925 \\
$\mathbf{B i q r}$ & 0,524 & 0,162 & 0,488 & 0,156 & 31,188 & 0,427 & $-185,007$ & 4,638 \\
$\mathbf{C q i r}$ & 0,602 & 0,186 & 0,574 & 0,184 & 34,832 & 0,477 & $-157,108$ & 3,939 \\
$\mathbf{2 A b} / \mathbf{C g}$ & 1,082 & 0,335 & 0,803 & 0,257 & 40,342 & 0,553 & $-98,468$ & 2,469 \\
${\mathbf{3 A b} / \mathbf{B t}_{\mathbf{1}}}$ & 2,196 & 0,679 & 1,301 & 0,417 & 52,370 & 0,717 & $-62,583$ & 1,569 \\
$\mathbf{4 B t x}_{\mathbf{2}}$ & 5,305 & 1,640 & 2,967 & 0,951 & 71,365 & 0,978 & $-30,398$ & 0,762 \\
$\mathbf{B t x}_{\mathbf{3}}$ & 1,953 & 0,604 & 0,772 & 0,247 & 39,128 & 0,536 & $-74,639$ & 1,871 \\
$\mathbf{5 B t}_{\mathbf{4}}$ & 1,977 & 0,611 & 1,660 & 0,532 & 61,857 & 0,847 & $-70,124$ & 1,758 \\
$\mathbf{B t}_{\mathbf{5}} / \mathbf{C r f}$ & 2,284 & 0,706 & 2,128 & 0,682 & 65,861 & 0,902 & $-57,688$ & 1,446 \\
$\mathbf{C r f}$ & 3,235 & $\mathbf{1 , 0 0 0}$ & 3,121 & $\mathbf{1 , 0 0 0}$ & 72,998 & $\mathbf{1 , 0 0 0}$ & $-39,888$ & $\mathbf{1 , 0 0 0}$ \\
\hline
\end{tabular}

concentrada em silte e areia muito fina entre 0,3 e $60 \mu \mathrm{m}$ de $(99 \%),(82 \%),(76 \%)$ e $(91 \%)$ respectivamente. Estes VAI's têm suas principais diferenças na fração areia muito fina e areia fina acima de $60 \mu \mathrm{m}$ onde $4 \mathrm{Btx}{ }_{2}$ tem melhor seleção de partículas. Os VAI's $5 \mathrm{Bt}_{4}, \mathrm{Bt}_{5} / \mathrm{Crf} \mathrm{e}$ Crf possuem uma distribuição mais próxima entre elas com uma seleção siltosa em torno de $20 \mu \mathrm{m}$, sendo Crf a que tem maior quantidade de areia muito fina e areia fina acima de $70 \mu \mathrm{m}$ (Figura 7).

As analises granulométricas indicam uma tendência que diferencia os VAI's do topo do perfil de alteração $\mathrm{A} / \mathrm{Cq}$ fração argila e silte gradando para Biqr e Cqir com uma distribuição na fração areia fina a areia grossa, VAI's da porção média do perfil de alteração $2 \mathrm{Ab} / \mathrm{Cg}, 3 \mathrm{Ab} / \mathrm{Bt}_{1}$ e $4 \mathrm{Btx}_{2}$ com uma distribuição silte e areia muito fina, seguido por $\left(\mathrm{Btx}_{3}\right)$ não uniforme mal selecionada e pelos VAI's da base do perfil de alteração $5 \mathrm{Bt}_{4}, \mathrm{Bt}_{5} / \mathrm{Crf}$ e $\mathrm{Crf}$ com uma distribuição mais próxima entre si, conforme descrição morfológica, sendo que nestes foram observadas grandes quantidades de mosqueamentos com transições onduladas, texturas argilo siltosas, consistência ligeiramente firme (pouco maciça) e ligeiramente plástica, diferenciando-se quanto à cor e estrutura.

De acordo com a análise mineralógica (Figura $8 \mathrm{e}$ Tabela 3), as amostras dos VAI's A/Cq, Biqr e Cqir são predominantemente compostas de caulinita e gibbsita em picos relativamente bem definidos, assimétricos e agudos na distância interplanar $\mathrm{d}=7,2$ e $4,8 \AA$, com proporções menores de anatásio $(3,5 \AA)$ e goethita $(2,4 \AA)$, podendo ser diferenciadas pelo conteúdo de quartzo (3,3 $\AA)$ e hematita $(2,7 \AA)$ em Biqr e Cqir. Nas amostras orientadas das frações finas aparecem ainda picos bem definidos de caulinita, os quais desaparecem no tratamento a $500^{\circ} \mathrm{C}$.

A amostra do VAI $2 \mathrm{Ab} / \mathrm{Cg}$ apresenta como composição básica caulinita e quartzo. Em quantidades inferiores hematita, anatásio, magnetita, gibbsita e

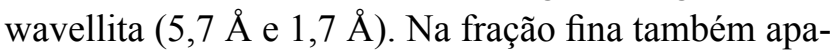
recem picos de caulinita, além da diminuição nos picos de minerais como quartzo $(3,3 \AA)$, gibbsita $(4,8 \AA) \mathrm{e}$ hematita $(3,6 \AA$ e $2,7 \AA)$. No VAI $3 \mathrm{Ab} / \mathrm{Bt}_{1}$ também há o predomínio dos picos de caulinita, quartzo, wavellita e magnetita com menores picos de anatásio e hematita, sem o mineral gibbsita. Em $4 \mathrm{Btx}_{2}$ também ocorre o aumento dos picos de wavellita, magnetita e quartzo, além das concentrações de caulinita, hematita e anatásio (Figura 8 e Tabela 3).

No VAI's Btx ${ }_{3}$ observa-se predominância de goethita e wavellita, além disso, apresenta proporções de anatásio, hematita, magnetita e caulinita. O VAI's $5 \mathrm{Bt}_{4}$ tem a caulinita como constituinte principal seguido com picos de gibbsita, hematita e magnetita $(4,8 \AA)$. Ambos os horizontes apresentam aumento nos picos de caulinita quando comparados com a fração fina significando boa estruturação dos mesmos. Já os VAI's Bt $/$ /Crf e Crf são predominantemente compostos por caulinita e quartzo. Nestes dois horizontes é possível apontar a existência de muscovita (10 $\AA$ ), com aumento dos picos nas frações finas aquecidas, tendo como principal diferença a quantidade de óxidos e hidróxidos de ferro e alumínio (Figura 8 e Tabela 3 ). 
Sardinha D. S. et al.
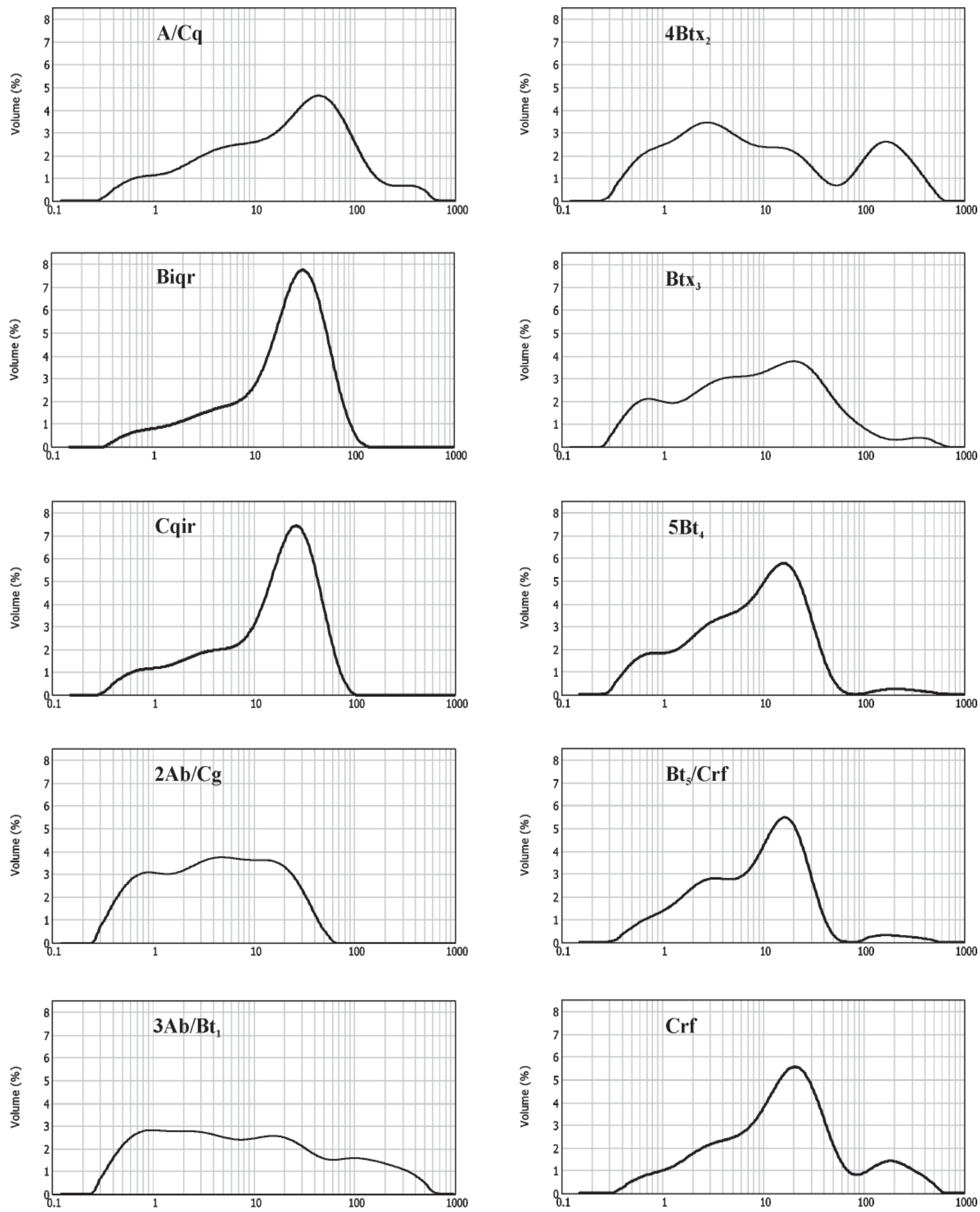

Figura 7 - Distribuição granulométrica dos VAI's analisados no perfil de alteração. 

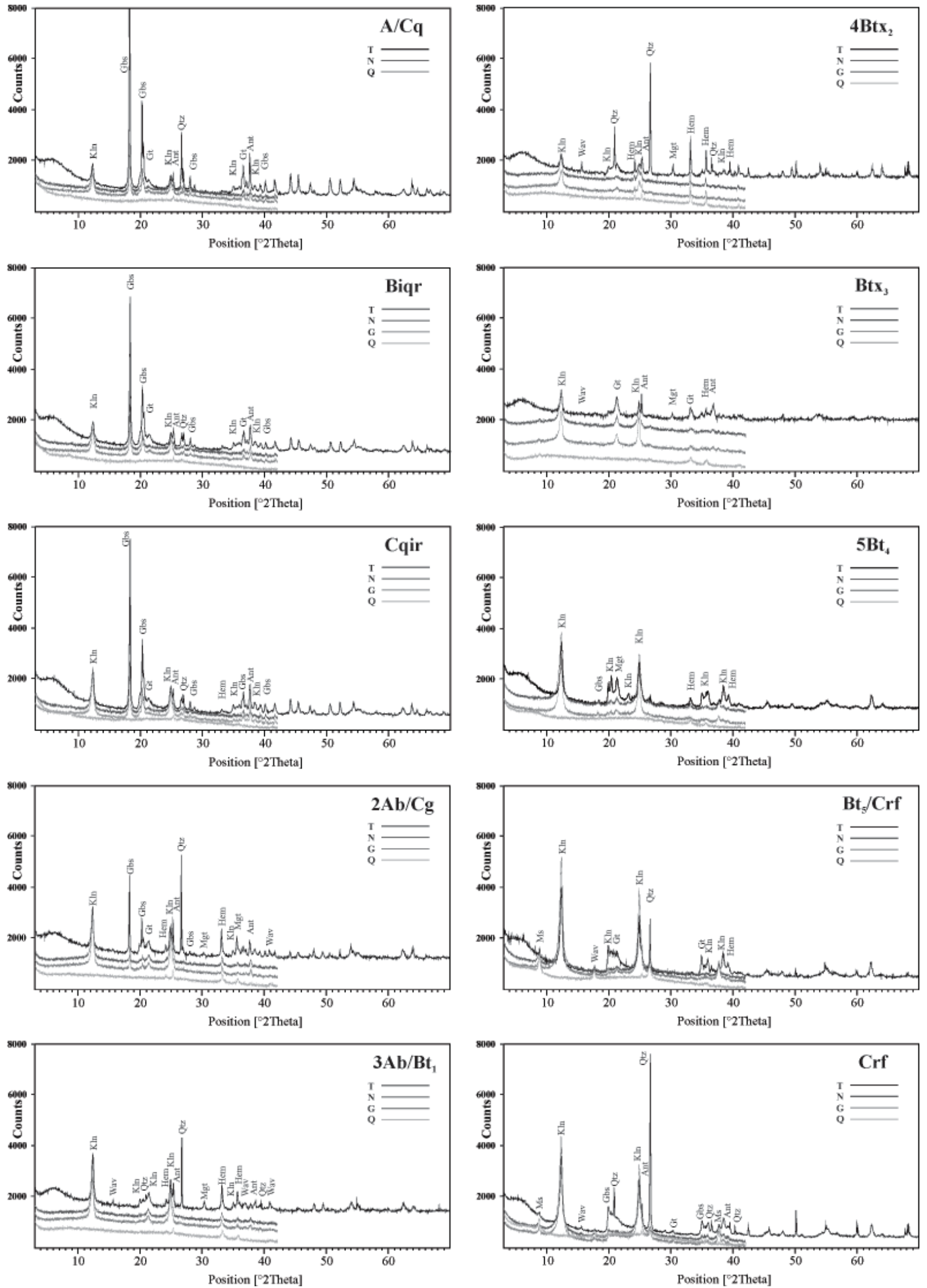

Figura 8 - Difratogramas das amostras do perfil de alteração. (T) amostra total; (N) fração fina natural; (G) fração fina glicolada; (Q) fração fina queimada; (Kln) Caulinita; (Gbs) Gibbsita; (Ant) Anatásio; (Qtz) Quartzo; (Hem) Hematita; (Gt) Goethita; (Mgt) Magnetita; (Wav) Wavellita; (Ms) Muscovita. 
Tabela 3: Mineralogia dos perfis de alteração VAI's. (Ms) Muscovita; (Kln) Caulinita; (Gt) Goethita; (Gbs) Gibbsita; (Hem) Hematita; (Ant) Anatásio; (Wav) Wavellita; (Mgt) Magnetita; (Qtz) Quartzo.

\begin{tabular}{cccccccccc}
\hline $\begin{array}{c}\text { VAI's } \\
\text { horizontes }\end{array}$ & Ms & Kln & Gt & Gbs & Hem & Ant & Wav & Mgt & Qtz \\
\hline $\mathbf{A} / \mathbf{C q}$ & -- & $\mathrm{Xx}$ & $\mathrm{Xx}$ & $\mathrm{X}$ & -- & $\mathrm{Xx}$ & -- & -- & $\mathrm{X}$ \\
Biqr & -- & $\mathrm{Xx}$ & $\mathrm{Xx}$ & $\mathrm{X}$ & -- & $\mathrm{Xx}$ & -- & -- & $\mathrm{Xx}$ \\
Cqir & -- & $\mathrm{X}$ & $\mathrm{Xx}$ & $\mathrm{X}$ & $\mathrm{X}$ & $\mathrm{Xx}$ & -- & -- & $\mathrm{Xx}$ \\
$\mathbf{2 A b} / \mathbf{C g}$ & -- & $\mathrm{X}$ & $\mathrm{Xx}$ & $\mathrm{XX}$ & $\mathrm{Xx}$ & $\mathrm{Xx}$ & $\mathrm{Xx}$ & $\mathrm{Xx}$ & $\mathrm{X}$ \\
$\mathbf{3 A b} / \mathbf{B t}$ & -- & $\mathrm{X}$ & -- & -- & $\mathrm{Xx}$ & $\mathrm{Xx}$ & $\mathrm{X}$ & $\mathrm{X}$ & $\mathrm{X}$ \\
$\mathbf{4 B t x}_{2}$ & -- & $\mathrm{Xx}$ & -- & -- & $\mathrm{Xx}$ & $\mathrm{Xx}$ & $\mathrm{X}$ & $\mathrm{X}$ & $\mathrm{X}$ \\
$\mathbf{B t x}_{3}$ & -- & $\mathrm{Xx}$ & $\mathrm{X}$ & & $\mathrm{Xx}$ & $\mathrm{Xx}$ & $\mathrm{X}$ & $\mathrm{Xx}$ & -- \\
$\mathbf{5 B t}$ & -- & $\mathrm{X}$ & -- & $\mathrm{Xx}$ & $\mathrm{Xx}$ & -- & -- & $\mathrm{Xx}$ & -- \\
$\mathbf{B t}_{5} / \mathbf{C r f}$ & $\mathrm{Xx}$ & $\mathrm{X}$ & $\mathrm{Xx}$ & -- & $\mathrm{Xx}$ & -- & $\mathrm{Xx}$ & -- & $\mathrm{Xx}$ \\
$\mathbf{C r f}^{\mathbf{n}}$ & $\mathrm{X}$ & $\mathrm{X}$ & $\mathrm{Xx}$ & $\mathrm{Xx}$ & -- & $\mathrm{Xx}$ & $\mathrm{Xx}$ & -- & $\mathrm{X}$ \\
\hline
\end{tabular}

Classificação semiquantitativa: $X=$ minerais principais; $X x=$ minerais acessórios .

A Figura 9a representa graficamente a resistência de cada amostra aos processos de desgaste/intemperismo para o índice de intemperismo potencial (WPI) versus índice de produtos (IP) em função da distância a partir da superfície da rocha para as amostras (VAI's) do perfil de alteração. Na rocha inalterada, os índices possuem valores elevados, com o progresso do intemperismo, os valores de WPI diminuem rapidamente devido às bases que são lixiviadas pela água que entra no sistema, e os valores de PI diminuem mais lentamente à medida que a sílica é perdida. Além disso, algumas amostras dos VAI's A/Cq, Biqr, Cqir, $2 \mathrm{Ab} / \mathrm{Cg}$, $3 \mathrm{Ab} / \mathrm{Bt}_{1}$ e Btx ${ }_{3}$ ultrapassam os campos de estabilidade dos argilominerais de caulinita (REICHE, 1943 apud COLMAN, 1982).

A Figura 9b indica que nos VAI's analisados ocorre a remoção de álcalis devido à lixiviação, sendo os conteúdos de $\mathrm{Fe}^{3+}$ e $\mathrm{Al}^{3+}$ superiores, e os de $\mathrm{Si}^{4+}$ inferiores aos da rocha-mãe meramente caulinizada. $\mathrm{O}$ diagrama representa a perda de $\mathrm{SiO}_{2}$ dos horizontes da base e o relativo ganho de $\mathrm{Al}_{2} \mathrm{O}_{3}$ e $\mathrm{Fe}_{2} \mathrm{O}_{3}$ nos horizontes intermediários e superiores. Com isso, argilas de baixa atividade podem ter se formado a partir de soluções muito diluídas, devido a um processo avançado de intemperismo, comum em zonas tropicais quentes com climas úmidos, formando perfis com laterização moderada A/Cq, Biqr e Cqir. Por outro lado, as argilas neoformados e/ou residuais podem indicar um processo de intemperismo incompleto e moderado comum em solos cujos horizontes não alcançaram estágios extremos de decomposição química, como ocorre em solos saturados ou com alternâncias climáticas, resultando em VAI's com laterização incipiente $2 \mathrm{Ab} / \mathrm{Cg}, 3 \mathrm{Ab} / \mathrm{Bt}_{1}$ e Btx ${ }_{3}$ e caulinização $4 \mathrm{Btx}_{2}, 5 \mathrm{Bt}_{4}, \mathrm{Bt}_{5} / \mathrm{Crf}$ e $\mathrm{Crf}$.

O material da base do perfil de alteração consiste em um Plintossolo com uma distribuição granulométrica (Figura 6) gradando do VAI Btx 3 para uma distribuição mais selecionada em torno de $20 \mu \mathrm{m}$ nos VAI's $5 \mathrm{Bt}_{4}$, $\mathrm{Bt}_{5} / \mathrm{Crf}$ e Crf que podem ser provenientes da alteração de rochas alcalinas efusivas (Figura 9). As cores se alternam, desde a matriz de coloração ocre e canalículos vermelhos, e de matriz vermelha com canalículos ocres (Figura 3), o que pode caracterizar uma transição entre um baixo e um alto estrutural em condições oxidantes e redutoras (anóxicas) respectivamente. A formação destes horizontes também pode estar condicionada ao impedimento à livre drenagem e pode ser resultante da existência de um lençol freático mais superficial em algum período do ano, o que ocorre em áreas de cotas inferiores com relevo plano, como depressões, baixadas, terços inferiores de encostas, ou devido à existência de camadas concrecionárias ou materiais de texturas argilosas, como nas áreas de surgente em condições de clima tropical úmido (ANJOS et al.., 2007; EMBRAPA, 2013).

As cores avermelhadas se dão essencialmente devido à oxidação de íons de ferro e titânio provenientes dos minerais primários e formação de minerais secundá- 

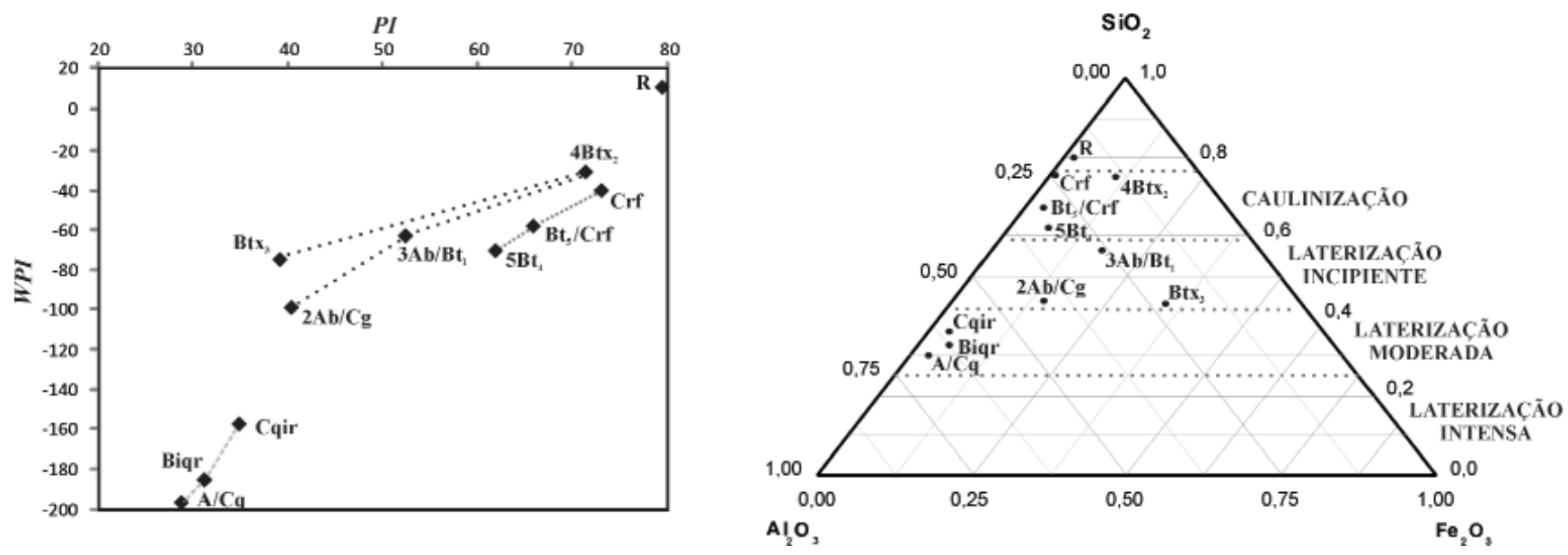

Figura 9 - (a) índice da mudança de resistência (IP x WPI) entre a amostra de rocha (R) de VALETON et al.. (1997) para as amostras de solos (A/Cq, Biqr, Cqir, 2Ab/Cg, 3Ab/Bt $\left., 4 B t x_{2}, B t x_{3}, 5 B t_{4}, B t_{5} / C r f e ~ C r f\right)$. Modificado: COLMAN (1982). (b) diagrama ternário (SiO ${ }_{2}$, $\left.\mathrm{Fe}_{2} \mathrm{O}_{3}, \mathrm{Al}_{2} \mathrm{O}_{3}\right)$ da amostra de rocha (R) de VALETON et al.. (1997) para as amostras de solos (A/Cq, Biqr, Cqir, 2Ab/Cg, 3Ab/Bt, $4 B t x_{2}$, $\mathrm{Btx}_{3}, 5 \mathrm{Bt}_{4}, \mathrm{Bt}_{5} / \mathrm{Crf}$ e Crf). Modificado: SCHELLMANN (1994, 2003).

rios (Tabela 1). Enquanto que as cores ocres prevalecem nos domínios de condições redutoras e formação de hidróxidos como gibbsita, caulinita e goethita (Tabela 3). Também foram observadas, em determinadas porções, cores mais escuras (tons de cinza) devido a uma residência prolongada da água no perfil, conforme a presença de mineral primário (muscovita), além de outros mal formados e/ou não definidos não passíveis de serem detectados por difração de raios X (Figuras $3 \mathrm{e}$ 8). Essas mudanças de cores podem estar relacionadas a flutuações do nível da água associadas aos movimentos tectônicos de ascendência e abatimentos sucessivos (Figuras 5, 6, 7 e 9).

Na maioria destes VAI's da base, pode ter ocorrido a perda de $\mathrm{K}^{+}$dos minerais das rochas primárias como a muscovita $\mathrm{KAl}_{2} \mathrm{Si}_{3} \mathrm{AlO}_{10}(\mathrm{OH})_{2}$ ainda presentes nos horizontes (Tabela 3), e em seguida a formação de argilominerais neoformados 1:1 como caulinitas $\mathrm{Al}_{2} \mathrm{Si}_{2} \mathrm{O}_{5}(\mathrm{OH})_{4}$ e por fim argilas oxídicas $\mathrm{AlOH}_{3}$ e $\mathrm{Fe}_{2} \mathrm{O}_{3} \cdot \mathrm{H}_{2} \mathrm{O}$ (Tabela 1 e Figura 4). As argilas neoformadas e oxídicas indicam um processo de intemperismo incompleto e moderado (minerais primários, bissialitização, monossialitização e alitização) comum em solos cujos horizontes não alcançaram estágios extremos de decomposição química como ocorre em solos saturados ou com alternâncias climáticas (Figuras 5, 6, 8 e 9).

Nos VAI's do topo do perfil de alteração A/Cq, Biqr e Cqir, foram encontradas camadas de bauxita endurecida (cárstica), cuja formação, muito provavel- mente se deu em ambiente árido (silicificação), que posteriormente lixiviou e/ou precipitou na forma de lateritas durante o tropicalismo e na concentração do alumínio (Figura 2). Além disso, as lateritas concrecionais encontradas no topo do perfil são mais enriquecidas em óxidos por se tratarem de produtos que resultam de períodos nos quais dominou o tropicalismo, o qual causou a remoção de outros elementos e resultou na concentração relativa de titânio, ferro e alumínio (Figuras 4, 5, 6 e 9).

As tendências de intemperismo, para os VAI's do topo do perfil de alteração, indicam perda de $\mathrm{Ca}^{2+}$ e $\mathrm{Na}^{+}$e formação de argilominerais como esmectitas $\mathrm{AlSi}_{2} \mathrm{O}_{6}(\mathrm{OH})_{2}$, que rapidamente sofreram intemperismo e se transformaram em argilas de baixa atividade como caulinitas $\mathrm{Al}_{2} \mathrm{Si}_{2} \mathrm{O}_{5}(\mathrm{OH})_{4}$ e oxídicas $\mathrm{Al}(\mathrm{OH})_{3}+$ $\mathrm{TiO}_{2}+\mathrm{SiO}_{2}+\mathrm{Fe}_{2} \mathrm{O}_{3}+\mathrm{Fe}_{3} \mathrm{O}_{4}+\mathrm{FeO}(\mathrm{OH})$ (Tabela 3). As esmectitas podem ter se formado em soluções ricas em $\mathrm{Si}^{4+}$, em regiões semi-áridas nas depressões onde o lençol freático traz o $\mathrm{Si}^{4+}$, ou próximas às rochas máficas intemperizadas. Por outro lado, as argilas de baixa atividade podem ter se formado a partir de soluções muito diluídas, devido a um processo avançado de intemperismo (monossialitização e alitização), comum em zonas tropicais quentes, com climas úmidos (Figuras $5,6,8$ e 9).

Nos VAI's localizados na porção média do perfil de alteração $2 \mathrm{Ab} / \mathrm{Cg}, 3 \mathrm{Ab} / \mathrm{Bt}_{1}$ e $4 \mathrm{Btx}_{2}$, há o que aparenta ser uma camada de solo orgânico (escuro), que prova- 
velmente corresponde a um resquício de paleolagos e que foram superpostos por fluxos de sedimentos (Figura 3). Em momentos de subsidência pode ter sido originado o material de granulação fina em conjunto com matéria orgânica (melanização), enquanto que nos momentos de ascensão, foram gerados materiais grosseiros pouco selecionados provenientes dos movimentos gravitacionais. Nestes VAI's predomina uma distribuição granulométrica fina a média, não selecionada com agilominerais 1:1 e argilas oxídicas (Tabela 3 e Figuras 7 e 8).

Estes horizontes/volumes de alteração intempérica (VAI's) apresentam os registros das interações policíclicas dos processos exo-endogênicos durante um ciclo ou durante vários momentos de atemporalidade geodinâmica caracterizando o perfil pedogênico e determinando seu potencial pedogeoquímico.

\subsection{Caldeira Vulcânica de Poços de Caldas e Evolução Pedogeoquímica}

Inicialmente e após a instalação da caldeira vulcânica de Poços de Caldas (Figura 10), datada de aproximadamente 72,4 Ma (THOMAZ FILHO \& RODRIGUES, 1999), os materiais foram submetidos à ação de agentes geodinâmicos sob clima bastante seco tropical/árido no Paleoceno (HOLMES et al.., 1992 apud TRICART, 1958) período em que foi promovida uma intensa silicificação sob condições mais alcalinas denominada de bauxitização cárstica. Este silcrete bauxítico passa a ser dissolvido pela ação das mudanças climáticas e interação das reativações tectônicas durante o Paleoceno a Eoceno Médio sob condições tropicais muito quentes de alta pluviosidade (HOLMES et al., 1992 apud TRICART, 1958) sendo profundamente intemperizado e, portanto latossolizado/laterizado/plintificado e em alguns locais com a presença de mantos cauliníticos e/ou nontroníticos/beidelíticos dependendo dos condicionantes morfoestruturais (JIMENEZ-RUEDA et al., 1993).

Posteriormente, os mantos foram truncados por efeito de novas reativações tectônicas que ocorreram durante a transição do Paleógeno para o Neógeno especificamente durante o Oligoceno/Mioceno (SCHORSCHER \& SHEA, 1991), época na qual possivelmente se apresenta uma forte inversão do relevo por efeito do desabamento da caldeira e com isto um alçamento das bordas da mesma, onde se encontravam depósitos lateríticos do tipo concrecionário por acumulação detrítica
(Figura 10). Estes mantos muito espessos recobriam áreas já laterizadas e que na atualidade constituem áreas de exploração de bauxita, assim como os pontos turísticos mais elevados das bordas da Caldeira hoje soerguidos.

No seu interior abatido, desenvolveram-se áreas lacustres que deram origem a proto drenos (HOLMES et al., 1992) que hoje configuram o Rio Pardo e Mogi-Guaçu que se dirigiam para NW e/ou SE. Algumas manifestações vulcânicas em pequenas crateras internas, aproximadamente 14 estruturas circulares representando intrusões menores (LOUREIRO \& SANTOS, 1988), que por sua vez só tiveram lançamento de cinzas (Figura 10). Estes vestígios de cinzas vulcânicas podem ser encontradas em depósitos associados à matéria orgânica de paleolagos, como no caso dos VAI's $3 \mathrm{Ab} /$ $\mathrm{Bt}_{1} \mathrm{e} \mathrm{Btx}_{3}$, os quais ainda apresentam fluxos detríticos mais grosseiros de pouca espessura e continuidade em formas quase laminares. Posteriormente, durante o Neógeno, se repetem as condições climáticas bastante secas (tropical/árido).

Os VAI's da base $5 \mathrm{Bt}_{4}, \mathrm{Bt}_{5} / \mathrm{Crf}$ e $\mathrm{Crf}$ e da porção média $2 \mathrm{Ab} / \mathrm{Cg}, 3 \mathrm{Ab} / \mathrm{Bt}_{1}$ e $4 \mathrm{Btx}_{2}$ do perfil de alteração foram provavelmente soterrados por depósitos relativamente modernos um pouco mais grosseiros granulometricamente e com riqueza mineral primária abundante em feldspatos e minerais secundários (argilominerais 1:1 e 2:1) detríticos que posteriormente foram neotransformados para interestratificados 2:1/1:1. Este soterramento ocorreu, muito provavelmente, a partir da alteração saprolítica dos regolitos silicificados durante o Pleistoceno Médio para Superior, que por sua vez passaram por uma transformação ainda muito mais recente durante o Pleistoceno Superior-Holoceno sob condições de alternância entre tropicalismo quente de alta pluviosidade e climas secos (HOLMES et al.., 1992).

Estes processos provavelmente foram responsáveis por uma latossolização profunda, deixando apenas vestígios de silcretes com presença de alguns bolsões de lateritas, constituindo veios verticais/horizontais/ oblíquos e que se encontram hoje sob condições de subtropicalidade em ambiente seco/subúmido que vem sendo novamente submetido a processos geodinâmicos de latossolização moderada com mobilização da sílica, conjuntamente com os elementos alcalinos e recristalizados dos óxidos de alumínio na forma de gibbsita, a qual se apresenta dominante nos difratogramas de raios $\mathrm{X}$ na sequência paleo-neopedogênica do topo do perfil $\mathrm{A} / \mathrm{Cq}$, Biqr e Cqir. 


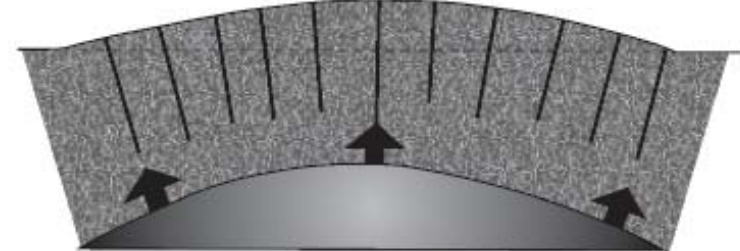

Estágio 1 - elevação do embasamento, distensão fratura e erosão

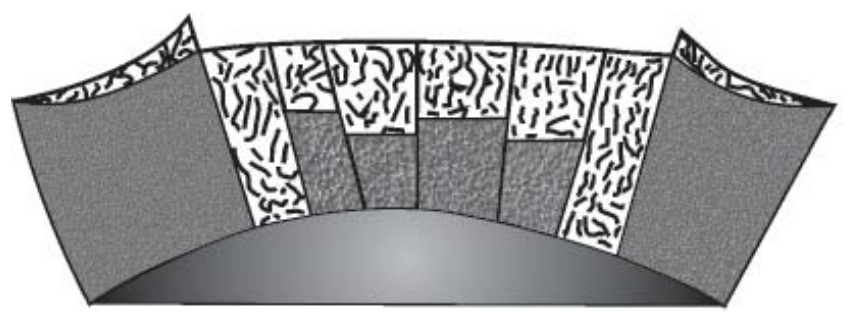

Estágio 3 - subsidência da caldeira

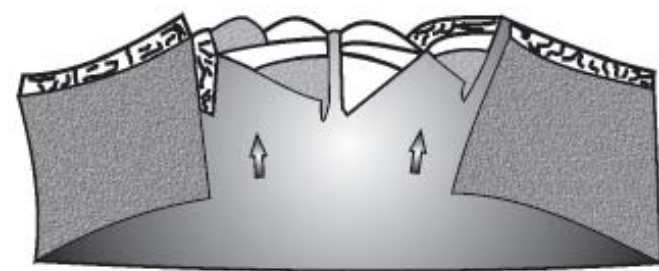

Estágio 5 - intrusões de nefelina sienitos, formação de diques com formas anelares e estruturas circulares

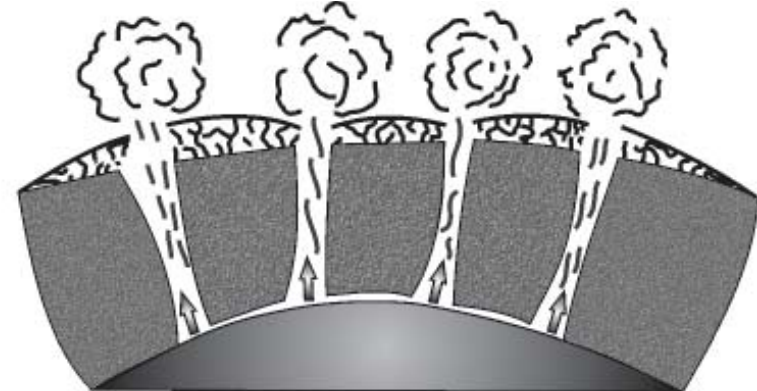

Estágio 2 - vulcanismo: fonólitos e vulcanoclásticas

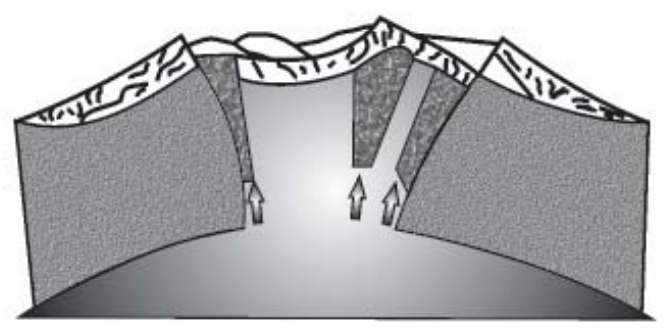

Estágio 4 - intrusão de fonólitos sub vulcânicos

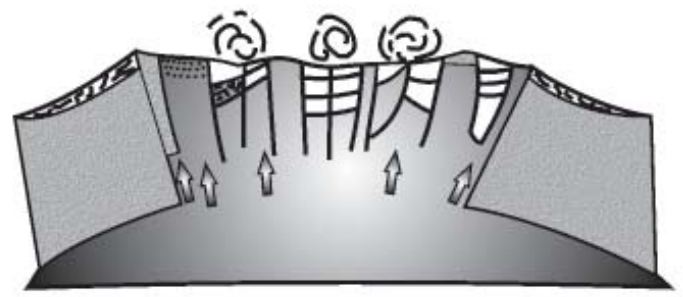

Estágio 6 - intrusões de eudialitas e nefelinas sienitos

Figura 10 - Modelo esquemático de evolução da caldeira vulcânica (Estágios 1 a 6). Modificado: LE BAS (1977); CHAPMAN et al.. (1991); SCHORSCHER \& SHEA (1992); HOLMES et al.. (1992).

O topo do perfil ainda apresenta vestígios de latossolização e lateritas centimétricas em placas deslocadas por prováveis movimentos estruturais no VAI Cqir, evidência dos processos de latossolização induzidas pelo clima antecedente tropical muito úmido durante o Holoceno Inferior a Médio, durante o qual foram dissolvidos/transformados os silcretes do Pleistoceno Médio-Superior. A cristalização e concentração das gibbsitas são notórias, assim como a neoformação de caulinita e interestratificados $2: 1 / 1: 1$ e a presença de wavellita como mineral testemunho da evolução sob condições de latossolização e laterização regional.

\section{Considerações Finais}

Quando se interpreta a evolução do manto de alteração através de um perfil representativo sob as condicionantes geoquímicas aplicadas nos volumes de alterações intempéricas (VAI's), elabora-se uma reconstrução paleoambiental do desenvolvimento intempérico sob determinadas condições geodinâmicas de cada uma das pedosequências/pedogeoquímicas presentes nela.

A sequência pedogênica/pedogeoquímica (i) topo do perfil, é formada pelos VAI's A/Cq, Biqr e Cqir, caracterizados pela formação em ambiente árido (silicificação), que posteriormente lixiviou e/ou precipitou na forma de lateritas durante o tropicalismo de alta pluviosidade, resultando na concentração do alumínio, lateritas concrecionais e reconcentração de titânio por processos geodinâmicos de latossolização moderada.

A sequência pedogênica/pedogeoquímica (ii) porção média do perfil apresenta um desenvolvimento sob condições de tropicalismo subúmido/subseco com con- 
dições favoráveis a instalações de lagos e com possíveis condições de reativação tectônica associada a vulcanismos. Os lançamentos de cinzas vulcânicas podem ser identificados nos sedimentos lacustres, e estão presentes no VAI Btx ${ }_{3}$, constituindo uma paleo-sequência residual que registra uma latossolização/laterização/plintificação muito profunda e prolongada sob a ação do clima tropical muito úmido e quente. Posteriormente, instala-se um clima mais úmido com tendência ao tropicalismo, lixiviando sílica, reintemperizando aqueles mantos regolíticos e sendo caracterizados como VAI $3 \mathrm{Ab} /$ $\mathrm{Bt}_{1}$. Este sub-conjunto é abatido e soterrado por outro conjunto regolítico originário da erosão e deposição em condições novamente lacustres caracterizado como VAI $2 \mathrm{Ab} / \mathrm{Cg}$. Com isso, estes VAI's Btx ${ }_{3}, 4 \mathrm{Btx}_{2}, 3 \mathrm{Ab} /$ $\mathrm{Bt}_{1}$ e $2 \mathrm{Ab} / \mathrm{Cg}$ apresentam registros de sua evolução sob condições alternantes de tropicalismo/subtropicalismo mais úmido ou mais seco durante os eventos de reativações tectônicas, associadas a processos degradacionais/ agradacionais, resultado das mudanças climáticas e da geração de um relevo movimentado, o que possivelmente caracteriza o deslocamento das evidências de paleolagos, assim como a presença de argilominerais do tipo 1:1 (caolinita) e interestratificados 2:1/1:1.

Finalmente uma sequência pedogênica/pedogeoquímica (iii) base do perfil pode ser definida morfogeneticamente nos VAI's designados como $\mathrm{Crf}, \mathrm{Crf} / \mathrm{Bt}_{5} \mathrm{e}$ $5 \mathrm{Bt}_{4}$. São caracterizados pela acumulação residual de sílica em altos estruturais em que a monossialitização é manifestada como produto final da profunda latossolização, laterização e plintificação do Cretáceo Final/ Paleoceno, correspondendo ao evento definido por Lester King (1956) como Superfície Sulamericana. Após uma erosão prolongada e profunda, que facilitaram a posterior implosão ou abatimento da Caldeira Vulcânica de Poços de Caldas, ocorreu o acúmulo dos mantos lateríticos concrecionários recobrindo alguns perfis completos da latossolização antecedente e que vieram a ser soerguidos nas suas bordas, deixando em seu interior as partes basais deste alto estrutural, caso dos volumes já concentados em $\mathrm{Crf}, \mathrm{Crf} / \mathrm{Bt}_{5}$ e $5 \mathrm{Bt}_{4}$ com forte tendência de dessilicificação.

\section{Agradecimentos}

Os autores agradecem os revisores anônimos pelas importantes contribuições, as quais melhoram a qualidade final do manuscrito.

\section{Referências Bibliográficas}

ANDERSON S.P.; DIETRICH W.E.; BRIMHALL G.H. Weathering profiles, massbalance analysis, and rates of solute loss: Linkages between weathering and erosion in a small, steep catchment. Geological Society of America Bulletin, 2002, vol. 114(9), pp. 1143- 1158.

ANJOS, L.H.C.; PEREIRA, M.G.; PÉREZ, D.V.; RAMOS, D.P. Caracterização e classificação de Plintossolos no município de Pinheiro - MA. Revista Brasileira de Ciência do Solo, vol. 31, 2007, pp. 1035-1044.

BARBOSA, I.O.; LACERDA, M.P.C.; BILICH, M.R. Relações pedomorfogeológicas nas chapadas elevadas do distrito federal. Revista Brasileira de Ciência do Solo, 2009, vol. 33, pp. 1373-1383.

BRIMHALL G.H.; CHADWICK O. A.; LEWIS C.J.; COMPSTON W.; WILLIAMS I.S.; DANTI K. J.; DIETRICH W.E.; POWER M.E.; HENDRICKS D.; BRATT J. Deformational Mass Transport and Invasive Processes in Soil Evolution. Science, 1991, vol. 255, pp. 695-702.

CHAPMAN, N.A.; McKINLEY, I.G.; SHEA, M.E.; SMELLIE, J.A.T. The Poços de Caldas Project: Summary and Implications for Radioactive Waste Management. Uppsala, SKB-Swedish Nuclear Fuel and Waste Management Co., 1991, $147 \mathrm{p}$.

COLMAN, S.M. Chemical weathering of basalts and andesites: evidence from weathering rinds. U.S. Geological Survey Professional Paper, vol. 1246, 1982, 51 p.

CPRM. Companhia de Pesquisa de Recursos Minerais. Projeto Sapucaí: relatório final. Escala 1:250.000. São Paulo: DNPM/CPRM, 5 volumes, 1979, 289 p.

EMBRAPA. Empresa Brasileira de Pesquisa Agropecuária. Sistema Brasileiro de Classificação de Solos. Brasilia, DF, 3 ed., 2013, 353p.

HASKINS D. Chemical and mineralogical weathering indices as applied to a granite saprolite in South Africa. The 10th IAEG International Congress, Nottingham, United Kingdom, 2006, Paper number 465, 14p.

HODSON M.E.; LANGAN S.J.; WILSON M.J. A sensitivity analysis of the PROFILE model in relation to the calculation of soil weathering rates. Applied Geochemistry, 1996, vol. 11 , pp. 835-844.

HODSON M.E. Comments on "Calculations of weathering rate and soil solution chemistry for forest soils in the Norwegian- 
Russian border area with the PROFILE model" by G. Koptsik, S. Tevedal, D. Aamlid and K. Venn. Applied Geochemistry, 2002, vol. 17, pp. 117-121.

HOLMES, D.C.; PITTY, A.E.; NOY, D.J. Geomorphological and hydrogeological features of the Poços de Caldas caldera analogue study sites. Journal of Geochemical Exploration, vol. 45, 1992, pp. 215-247.

HUDSON D.M. Petcal (version 2.1) an expanded and personal computer compatible basic language program for petrologic calculations. Nevada Bureau of Mines and Geology, Open File Report 88-3, 1988, 25p.

IBGE. Instituto Brasileiro de Geografia e Estatística. Manual Técnico de Pedologia. Diretoria de Geociências. Coordenação de Recursos Naturais e Estudos Ambientais, 2007, 2 ed., 316p.

INB. Indústrias Nucleares do Brasil. Programa de Recuperação de Áreas Degradadas (PRAD). UTM - Caldas - Minas Gerais. $\mathrm{N}^{\circ}$ Projeto099-515-3023. Elaboração R.L. Mapa Geológico Regional (2), 22/08/2011.

JIMÉNEZ-RUEDA J.R., NUNES E., MATTOS J.T. Caracterização fisiográfica e morfoestrutural da Folha São José de Mipibu, RN. Geociências, São Paulo, 1993, 12(2):481-491.

JIMÉNEZ-RUEDA, J.R.; PESSOTTI, J.E.S.; MATTOS, J.T. Modelo para o estudo da dinâmica evolutiva dos aspectos fisiográficos dos pantanais. Pesq. Agrop. Bras., Brasília, v.33, Número Especial, 1998, pp. 1763-1773.

KRAUSKOPF, K.B. Introduction to Geochemistry. McGrawHill, 3o ed., 1995, 647 p.

LACERDA, M.P.C.; ANDRADE, H.; QUÉMÉNEUR, J.J.G. Pedogeoquímica em perfis de alteração na região de Lavras (MG). I - elementos maiores - óxidos constituintes. Revista Brasileira de Ciência do Solo, vol.26, 2002a, pp. 75-85.

LACERDA, M.P.C.; ANDRADE, H.; QUÉMÉNEUR, J.J.G. Pedogeoquímica em perfis de alteração na região de Lavras (MG). II - elementos menores e elementos das terras raras. Revista Brasileira de Ciência do Solo, vol.26, 2002b, pp. 87-102.

LASHERAS ADOT E.; PLANO S.C.; REIXACH J.G. VALENCIA D.E. Geochemical inheritance of soils that develop from volcanic rocks (Navarra, Western Pyrenees). Geoderma, 2006, Vol. 135, pp. 38- 48.

LE BAS, M.J. Carbonatite-Nepheline volcanism. John Wilet \& Sons, Ltd. Bristol, Great Britain, 1977, 347p.

LESTER KING, C. A geomorfologia do Brasil Oriental. Revista
Brasileira de Geografia, 1957, no2, pp. 03-119.

LOUREIRO, F.E.L.; SANTOS, R.C. The intra-intrusive uranium deposits of Poços de Caldas, Brazil. Ore Geology Reviews, 1988, 3, 227-240.

MELFI A.J.; PEDRO G. Estudo geoquímico dos solos e formações superficiais do Brasil. Parte 1 - Caracterização e repartição dos principais tipos de evolução pedogeoquímica. Revista Brasileira de Geociências, 1977, vol. 7, pp. 271-286.

MUNSELL. Soil-color charts. Munsell color, 2010, Grand Rapids, MI, USA.

PMPC. Prefeitura Municipal de Poços de Caldas. Revisão do Plano Diretor. Poços de Caldas: Secretaria de Planejamento e Coordenação, 2006, 178 p.

PMPC. Prefeitura Municipal de Poços de Caldas. Zoneamento Ambiental do Município de Poços de Caldas (MG): subsídios ao planejamento territorial. Relatório técnico. Poços de Caldas, $2007,41 p$

PMPC. Prefeitura Municipal de Poços de Caldas. Perfil Municipal. Disponível em http://200.195.60.10/. Acesso em 12/03/2012.

PRICE J.R.; VELBEL M.A. Chemical weathering indices applied to weathering profiles developed on heterogeneous felsic metamorphic parent rocks. Chemical Geology, 2003, Vol. 202, pp. 397- 416.

ROLLINSON H. Using Geochemical data: evaluation, presentation, interpretation. London: Longman Group, 1993, $352 \mathrm{p}$.

RUXTON, B.P. Measures of the degree of chemical weathering of rocks. Journal of Geology, 1968, vol.76, pp. 518-527.

SCHELLMANN, W. Discussion of A critique of the Schellmann definition and classification of laterite by R.P. Bourman and C.D. Ollier (Catena 47, 117-131). Catena, 2003, vol. 52, pp. 77-79.

SCHELLMANN, W. Geochemical differentiation in laterite and bauxite formation. Catena, 1994, vol. 21, pp. 131-143.

SCHOBBENHAUS C.; CAMPOS D.A.; DERZE G.R.; ASMUS H.E. Geologia do Brasil. Brasília, DNPM, 1984, 435p.

SCHORSCHER H.D.; SHEA, M.E. The regional geology of the Poços de Caldas alkaline complex: mineralogy and geochemistry of selected nepheline syenites and phonolites. Journal of Geochemical Exploration, 1992, vol. 45, pp. 25-51.

SIQUEIRA, A.C.A.; MAGINI, C.; DANTAS, E.L.; FUCK, R.A.; SASAKI, J.M. Lateritas do Domínio Médio Coreaú - 
Comportamento geoquímico de mantos lateríticos do Noroeste do Estado do Ceará. Brazilian Journal of Geology, 2014, vol. 44(2), pp. 249-264.

SUGUIO K. Geologia sedimentar. São Paulo: Edgard Blucher, $1^{\circ}$ edição, 2003, 400p.

TEIXEIRA, W.; TOLEDO, M.C.M.; FAIRCHILD, T.R.; TAIOLI, F. (Orgs.) Decifrando a Terra. São Paulo: Oficina de Textos, 2000. 568 p.

THOMAZ FILHO A.; RODRIGUES A.L. O alinhamento de rochas alcalinas Poços de Caldas-Cabo Frio (RJ) e sua continuidade na cadeia Vitória-Trindade. Revista Brasileira de Geociências, 1999, 29(2):189-194.
VALETON, I.; SCHUMANN, A.; VINX, R.; WIENEKE, M. Supergene alteration since the upper cretaceous on alkaline igneous and metasomatic rocks of the Poços de Caldas ring complex, Minas Gerais, Brazil. Applied Geochemistry, vol. 12, 1997, pp. 133-154.

VIEIRA, L. S. Manual da ciência do solo: com ênfase aos Solos Tropicais. São Paulo: Editora agronômica CERES Ltda, 1988, 464 p.

ZAINE, J. E. et al. Estudo de caracterização geológicogeotécnica aplicado ao planejamento rural e urbano do município de Poços de Caldas, MG. Rio Claro, SP: Fundação de Apoio à Pesquisa, Ensino e Extensão - FUNEP, 2008. 78 p. 